\title{
Hybrid Coatings Enriched with Tetraethoxysilane for Corrosion Mitigation of Hot-Dip Galvanized Steel in Chloride Contaminated Simulated Concrete Pore Solutions
}

\author{
Rita B. Figueira ${ }^{1, *}$, Emanuela Callone ${ }^{2}$, Carlos J. R. Silva ${ }^{3}$, Elsa V. Pereira ${ }^{1}$ and Sandra Dirè ${ }^{2}$ \\ 1 LNEC, National Laboratory for Civil Engineering, Av. do Brasil 101, Lisboa 1700-066, Portugal; \\ epereira@lnec.pt \\ 2 "Klaus Müller" NMR Laboratory, Department of Industrial Engineering, University of Trento, \\ Via Sommarive, 9, Trento 38123, Italy; emanuela.callone@unitn.it (E.C.); sandra.dire@unitn.it (S.D.) \\ 3 Centro de Química, University of Minho, Campus de Gualtar, Braga 4710-057, Portugal; \\ csilva@quimica.uminho.pt \\ * Correspondence: rita@figueira.pt or rmfigueira@lnec.pt; Tel.: +351-217-147-145
}

Academic Editor: Silvia Gross

Received: 26 January 2017; Accepted: 14 March 2017; Published: 17 March 2017

\begin{abstract}
Hybrid sol-gel coatings, named $\mathrm{U}(\mathrm{X})$ :TEOS, based on ureasilicate matrices $(\mathrm{U}(\mathrm{X}))$ enriched with tetraethoxysilane (TEOS), were synthesized. The influence of TEOS addition was studied on both the structure of the hybrid sol-gel films as well as on the electrochemical properties. The effect of TEOS on the structure of the hybrid sol-gel films was investigated by solid state Nuclear Magnetic Resonance. The dielectric properties of the different materials were investigated by electrochemical impedance spectroscopy. The corrosion behavior of the hybrid coatings on HDGS was studied in chloride-contaminated simulated concrete pore solutions (SCPS) by polarization resistance measurements. The roughness of the HDGS coated with hybrids was also characterized by atomic force microscopy. The structural characterization of the hybrid materials proved the effective reaction between Jeffamine ${ }^{\circledR}$ and 3-isocyanate propyltriethoxysilane (ICPTES) and indicated that the addition of TEOS does not seem to affect the organic structure or to increase the degree of condensation of the hybrid materials. Despite the apparent lack of influence on the hybrids architecture, the polarization resistance measurements confirmed that TEOS addition improves the corrosion resistance of the hybrid coatings $(\mathrm{U}(\mathrm{X})$ :TEOS) in chloride-contaminated SCPS when compared to samples prepared without any TEOS $(\mathrm{U}(\mathrm{X}))$. This behavior could be related to the decrease in roughness of the hybrid coatings (due TEOS addition) and to the different metal coating interaction resulting from the increase of the inorganic component in the hybrid matrix.
\end{abstract}

Keywords: sol-gel; hybrids; coatings; corrosion mitigation; alkaline environment; chlorides

\section{Introduction}

Corrosion of reinforcement is one of the major causes of damage of reinforced concrete structures (RCS) worldwide [1-6]. The durability requirements, particularly in harsh environments such as marine and industrial, are not always achieved [5,7-10]. Generally, the major causes for corrosion of reinforcement in concrete are carbonation of concrete due to concrete acidification after reaction with atmospheric carbon dioxide, and/or the presence of chloride ions. In marine environments, chloride ions can penetrate the porous structure of concrete and reach the steel [6]. In other cases, a recurrent malpractice is the use of chloride-contaminated coarse aggregates and water constituents leading to the presence of chloride ions in the concrete since the beginning [11,12]. 
The reliability and the durability of RCS are crucial for the society and its economy due to the high costs of structure conservation and maintenance. Therefore, in order to increase their service life in aggressive environments, several methods have been proposed [7,13-15]. The use of hot-dip galvanized steel (HDGS) has been widely recognized as an effective measure to increase the service life of RCS [15-17]. Nevertheless, when the HDGS is in contact with concrete pore solutions, whose $\mathrm{pH}$ is typically above 12.5 , zinc corrosion occurs [16,18-24]. This leads to zinc layer consumption until either, a passivation layer is formed, or until the entire zinc layer is consumed. Commonly, to mitigate this initial corrosion process, procedures such as increasing the chromate content of the concrete mixture or the use of chromate conversion layers have been widely applied. However, due to the hard restrictions imposed on the use of $\mathrm{Cr}(\mathrm{VI})$, a growing interest in developing innovative materials for chromate conversion layers replacement has led to the synthesis and assessment of several organic-inorganic hybrid sol-gel materials [25-31].

Ureasilicate $(\mathrm{U}(\mathrm{X}))$ coatings were proven to behave as a physical barrier in highly alkaline environments $(\mathrm{pH}>12.5)$ [32-35] and to be effective in hindering the chloride ion diffusion to the substrate. Therefore, these materials mitigate the corrosion reaction rate on the metal surface of HDGS in chloride contaminated SCPS [36]. $U(X)$ hybrids are prepared from 3-isocyanate propyltriethoxysilane (ICPTES) and di-amino functionalized polyether (hereafter referred generically as Jeffamine ${ }^{\circledR}$ ) $[27,33-35]$. The polymeric chains of these polyetheramines are block co-polymers based on propylene-ethylene-ethylene glycols sequences. The Jeffamine ${ }^{\circledR}$ molecules establish a chemical link with the inorganic network created by the condensation reactions of the organosilane [32]. Improved performance was obtained for $\mathrm{U}(\mathrm{X})$ samples prepared with lower molecular weight (MW) of Jeffamine ${ }^{\circledR}$ $\left(\approx 230\right.$ and $\left.400 \mathrm{~g} \cdot \mathrm{mol}^{-1}\right)[27,33-35]$ rather than with samples prepared with higher MWs of Jeffamine ${ }^{\circledR}$ $\left(\approx 600,900\right.$ and $\left.2000 \mathrm{~g} \cdot \mathrm{mol}^{-1}\right)$ [32].

This study aimed to improve the corrosion protection properties of $\mathrm{U}(\mathrm{X})$ materials, prepared with high MWs of Jeffamine ${ }^{\circledR}$ by increasing the inorganic component of the hybrid matrices both by increasing the content of ICPTES [37] and adding tetraethoxysilane (TEOS). Therefore, new $\mathrm{U}(\mathrm{X})$ compositions were obtained employing a Jeffamine:ICPTES molar ratio 1:4.16 and adding controlled amounts of TEOS into the reaction mixture. The obtained hybrid coatings were tested in alkaline environments.

TEOS was chosen because its properties and reactivity are quite well known at different $\mathrm{pH}$ and temperatures $[25,38,39]$. It is a silica precursor available with a higher purity grade, presents a relatively slow and controllable rate of reaction, and it is less toxic when compared to tetramethoxysilane (TMOS). Organic-inorganic hybrids based on TEOS can produce, at low temperatures, homogeneous films on large areas of substrates, with improved transparency [25]. Moreover, organic-inorganic hybrids based on TEOS are low cost. Indeed, this precursor, for similar purity grades, is about four times cheaper than organosilanes commonly employed such as 3-glycidoxypropyltrimethoxy-silane (GPTMS) and half of the price of methyltriethoxysilane (MTES) [25].

The structural features of the $U(X)$ sol-gel films and the effect of TEOS addition were investigated by solid state Nuclear Magnetic Resonance. The effect of increasing the inorganic components on the dielectric properties of the hybrid films was studied by electrochemical impedance spectroscopy to determine the respective conductivity and dielectric constant. The electrical properties are strongly affected by the structural matrix of the hybrid materials. The effect of stiffening induced by the silicate chains resulting from the condensation of inorganic components is opposed by the liquid-like properties from the presence of organic chain components. Therefore, the kinetics and extension of ions movement across materials is dependent on the organic and inorganic components concentration and interactions. The corrosion resistance of the different hybrid coatings synthesized (with and without TEOS) was investigated, in chloride-contaminated simulated concrete pore solutions, by polarization resistance. The morphology of the coatings (roughness) was also assessed by atomic force microscopy. 


\section{Experimental Section}

\subsection{Materials}

Jeffamine $^{\circledR}$ ED-600, Jeffamine ${ }^{\circledR}$ ED-900 and Jeffamine ${ }^{\circledR}$ ED-2000 (Fluka), 3-Isocyanate propyltriethoxysilane (ICPTES, 95\%, Aldrich) and tetraethoxysilane (TEOS, 98\%, Aldrich) were purchased from Sigma-Aldrich, Química, Sintra, Portugal, and used as supplied. Absolute ethanol (EtOH, absolute 98\%, Riedel-de-Haën (Sigma-Aldrich Química, Sintra, Portugal) and citric acid monohydrate (Merck, Darmstadt, Germany) were likewise used as provided. Ultra-pure water $(0.055-0.060 \mu \mathrm{S} / \mathrm{cm}$ ) obtained from a Purelab Ultra System (Elga, (Lab Water-Veolia Water Solutions \& Technologies, Paris, France)) was used.

\subsection{Sol-Gel Synthesis of Hybrid Ureasilicate Coatings}

The experimental steps involved in the synthesis of the hybrid sol-gel matrices, to produce films and coatings on HDGS samples, are shown in Figure 1.

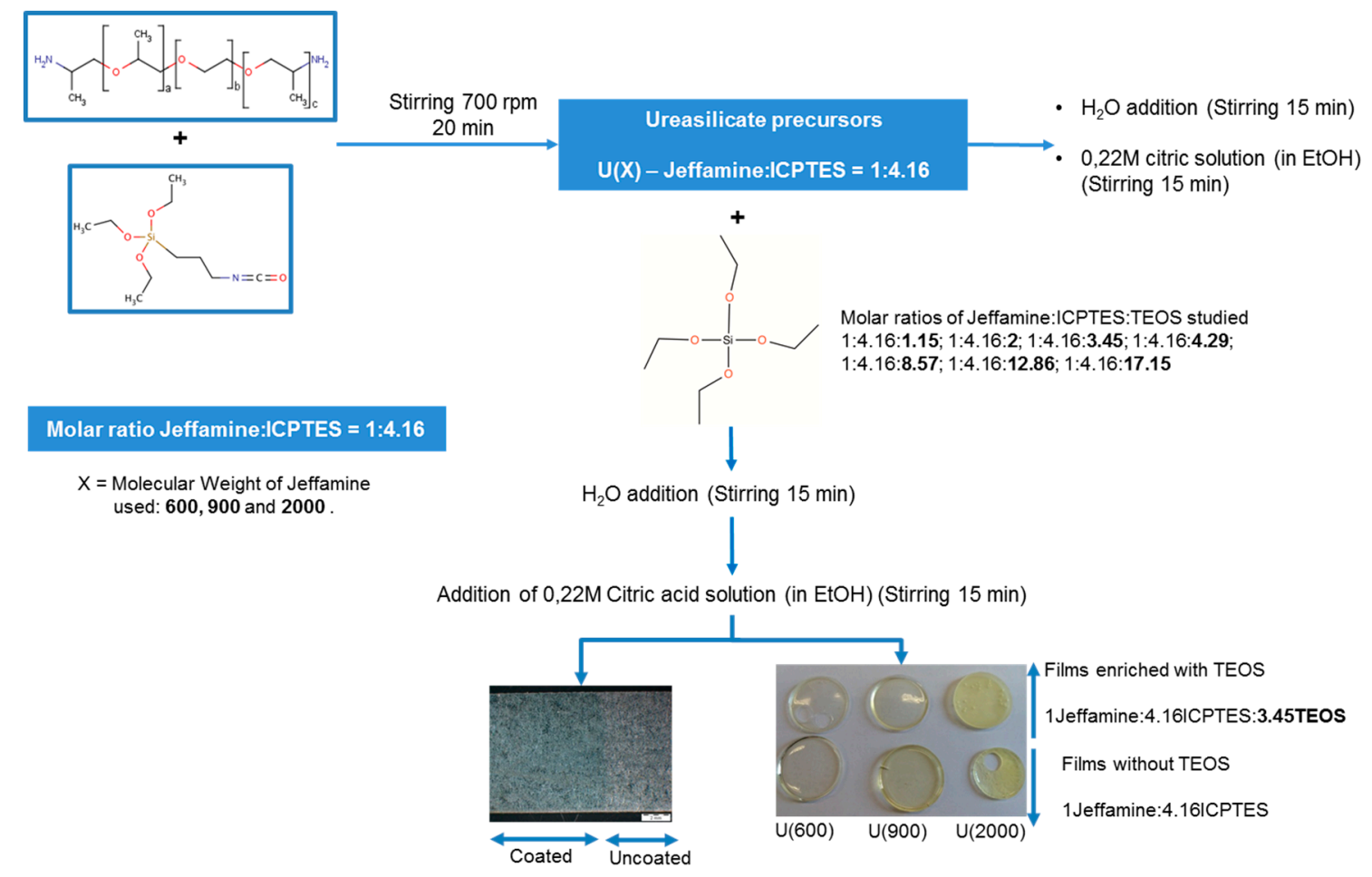

Figure 1. Schematic representation of the main steps involved in the production of hybrid films and coatings with and without tetraethoxysilane (TEOS).

Different materials were prepared as films or coatings on HDGS with and without TEOS (U(600), $\mathrm{U}(600)$ :TEOS, $\mathrm{U}(900), \mathrm{U}(900)$ :TEOS, $\mathrm{U}(2000)$ and $\mathrm{U}(2000)$ :TEOS). Three $\mathrm{U}(\mathrm{X})$ precursors were obtained by mixing a stoichiometric amount (1:4.16) of Jeffamine ${ }^{\circledR}$ (ED-600, ED-900 and ED-2000) and ICPTES in a closed vessel (Table 1). Other materials with different molar ratios of Jeffamine:TEOS were prepared. In all the syntheses, the molar ratios $\mathrm{H}_{2} \mathrm{O}$ :Jeffamine and Jeffamine:Citric Acid were kept constant by controlling the amounts of $0.2 \mathrm{M}$ Citric acid solution and water added. The synthesis was performed using a standard procedure as described in literature $[27,32,36]$. The samples synthesis was performed with adding water in stoichiometric amount to hydrolyze the ethoxyde groups of both ICPTES and TEOS. 
Table 1. Molar ratios of the different hybrid films and coatings synthesized.

\begin{tabular}{|c|c|c|c|c|c|}
\hline \multirow{2}{*}{ Samples } & \multirow{2}{*}{$\begin{array}{l}\text { MW of } \\
\text { Jeffamine }\end{array}$} & \multicolumn{4}{|c|}{ Molar Ratios } \\
\hline & & Jeffamine:ICPTES & Jeffamine:TEOS & $\mathrm{H}_{2} \mathrm{O}$ :Jeffamine & Jeffamine:Citric Acid \\
\hline $\mathrm{U}(600)$ & & & n.a. & & \\
\hline $\mathrm{U}(600): 3.45 \mathrm{TEOS}$ & & & $1: 3.45$ & & \\
\hline U(600):4.29TEOS & 600 & 1:4.16 & $1: 4.29$ & $29.67: 1$ & $1: 0.22$ \\
\hline $\mathrm{U}(600): 12.86 \mathrm{TEOS}$ & & & $1: 12.86$ & & \\
\hline $\begin{array}{c}\mathrm{U}(900) \\
\mathrm{U}(900): 3.45 \mathrm{TEOS}\end{array}$ & 900 & $1: 4.16$ & $\begin{array}{c}\text { n.a. } \\
\text { 1:3.45 }\end{array}$ & $29.67: 1$ & $1: 0.22$ \\
\hline $\begin{array}{c}\mathrm{U}(2000) \\
\mathrm{U}(2000): 3.45 \mathrm{TEOS}\end{array}$ & 2000 & 1:4.16 & $\begin{array}{c}\text { n.a. } \\
1: 3.45\end{array}$ & $29.67: 1$ & $1: 0.22$ \\
\hline
\end{tabular}

For $\mathrm{U}(\mathrm{X})$ matrices that were enriched with TEOS, the appropriate quantity was added to each ureasilicate, according to the molar ratios indicated in Table 1 (U(600):TEOS, U(900):TEOS and $\mathrm{U}(2000)$ :TEOS). In the third step, $0.22 \mathrm{M}$ solution of citric acid in ethanol solution was added and stirred during $15 \mathrm{~min}$. After that, distilled water was added and the final mixture was left to react for further $15 \mathrm{~min}$.

\subsection{Preparation of the Hybrid Films and Coatings on Hot-Dip Galvanized Steel}

Hybrid matrices were synthesized to produce films or coatings deposited on HDGS substrate. The hybrid films were prepared according to the ratios indicated in Table 1 . The coatings prepared without TEOS on HDGS were U(600), U(900) and U(2000); all with a molar ratio of Jeffamine:ICPTES equal to 1:4.16. For the samples enriched with TEOS, only the ones using a ratio of Jeffamine:TEOS equal to 1:3.45 (identified by U(600):3.45TEOS, U(900):3.45TEOS and U(2000):3.45TEOS) were prepared as coatings.

Both coatings and films samples, based on $\mathrm{U}(\mathrm{X})$ and $\mathrm{U}(\mathrm{X})$ enriched with TEOS, identified as $\mathrm{U}(\mathrm{X})$ :TEOS, were produced from a single batch of precursor solution (in a sol form). For the preparation of the $\mathrm{U}(\mathrm{X})$ films, the remainder of the prepared mixture was transferred to a petri dish (polystyrene, $2 \mathrm{~cm}$ of diameter, supplied by Sarstedt). All the U(X) enriched with TEOS (U(X):TEOS) films (Table 1) were transferred to a Teflon ${ }^{\mathrm{TM}}$ mold (with an inner diameter of $3 \mathrm{~cm}$ ) and covered with Parafilm ${ }^{\circledR}$.

The HDGS samples were obtained from commercially available plates and cut to dimensions of $5.0 \mathrm{~cm} \times 1.0 \mathrm{~cm} \times 0.1 \mathrm{~cm}$. The HDGS samples had an average zinc thickness of $16 \mu \mathrm{m}$ on both sides. Before coating deposition, the HDGS metal plates were degreased with acetone and dried at room temperature. Coated HDGS samples were prepared by dipping the metallic plates of HDGS in the synthesized sol mixture using a dip coater (Nima, model DC Small). The hybrid coatings were deposited by one and three consecutive dip steps at a withdrawal speed of $10 \mathrm{~mm} \cdot \mathrm{min}^{-1}$, without residence time. Producing samples coated by either one or three consecutive dip steps, allowed the assessment of performance against corrosion of thinner and thicker coatings in chloride-contaminated SCPS. All the synthesized hybrid films and the coated HDGS samples were immediately placed in an incubator-compressor (ICP-400 Memmert, (Memmert GmbH + Co. KG, Schwabach, Germany)) and kept at $40^{\circ} \mathrm{C}$ for 15 days. The films for the solid state NMR analyses, after the curing process, were removed from the petri dishes $(\mathrm{U}(\mathrm{X}))$ and from the Teflon ${ }^{\mathrm{TM}}$ mold $(\mathrm{U}(\mathrm{X})$ :TEOS) and smashed to form a powder.

\subsection{Structural Characterization of the Hybrid Materials by Solid State Nuclear Magnetic Resonance (NMR)}

Solid state NMR analyses were carried with a Bruker $400 \mathrm{WB}$ spectrometer operating at a proton frequency of $400.13 \mathrm{MHz}$. NMR spectra were acquired under the following conditions: ${ }^{13} \mathrm{C}$ frequency: $100.48 \mathrm{MHz}, \pi / 2$ pulse $3.4 \mu \mathrm{s}$ cross polarization sequence, contact time $2000 \mu \mathrm{s}$, decoupling length $6.3 \mu$ s, recycle delay: $5 \mathrm{~s}, 5 \mathrm{k}$ scans. ${ }^{29} \mathrm{Si}$ frequency: $79.48 \mathrm{MHz}, \pi / 2$ pulse $3.9 \mu \mathrm{s}$. Single pulse sequence: $\pi / 4$ pulse $3.9 \mu \mathrm{s}$, decoupling length $6.3 \mu \mathrm{s}$, recycle delay $100 \mathrm{~s}, 2 \mathrm{k}$ scans. Samples were packed in $4 \mathrm{~mm}$ zirconia rotors, which were spun at $9 \mathrm{kHz}$ under air flow. Adamantane and $\mathrm{Q}_{8} \mathrm{M}_{8}$ were used 
as external secondary references. Liquid NMR data were recorded on a Bruker $400 \mathrm{WB}$ spectrometer operating at a proton frequency of $400.13 \mathrm{MHz}$ equipped with a $5 \mathrm{~mm}$ BBO probe under the following conditions: ${ }^{13} \mathrm{C}$ frequency: $100.48 \mathrm{MHz}$, power gated single pulse sequence, $\pi / 6$ pulse $2.7 \mu \mathrm{s}$, with $80 \mu$ s waltz decoupling, recycle delay: $30 \mathrm{~s}, 128$ scans. Bruker TopSpin software was used for the lineshape analysis. The results were considered acceptable with confidence level of $95 \%$.

\subsection{Glow Discharge Optical Emission Spectroscopy (GD-OES)}

The chemical composition depth profiling of the coatings applied on the HDGS substrates was performed using a glow discharge optical emission spectrometer on coated and uncoated substrates. A LECO glow discharge GD OES 850A, with a radiofrequency source and a $700 \mathrm{~V}$ RMS was used and the samples were analyzed under argon atmosphere.

\subsection{Characterization of the Dielectric Properties of the Hybrid Films by Electrochemical Impedance Spectroscopy (EIS)}

EIS measurements were carried out to characterize the electrical impedance, dielectric constant and capacitance of the prepared hybrid films. Two Au disc electrodes $(10 \mathrm{~mm}$ diameter and $250 \mu \mathrm{m}$ thickness) and a support cell (Figure 2) adapted from a previous model [40] were used. All measurements were performed at room temperature using an Impedance/Gain-Phase Analyzer (Model 1260A, Solartron-Schumberger) and a Potentiostat/Galvanostat (Model 1287A, Solartron-Schlumberger (AMETEK, Inc., Berwyn, PA, USA)) controlled by a PC using Zplot software (Solartron-Schlumberger, version 2.9c). Measurements were taken by applying a $10 \mathrm{mV}$ (peak-to-peak, sinusoidal) electrical potential within a frequency range from $1 \times 10^{5} \mathrm{~Hz}$ to $0.01 \mathrm{~Hz}$ (10 points per decade) between the two Au electrodes at open circuit potential. The frequency response data of the hybrid films studied were displayed in a Nyquist plot, using ZView software (Solartron-Schlumberger, version $2.9 \mathrm{c}$ ) that was also used for data fitting purposes.
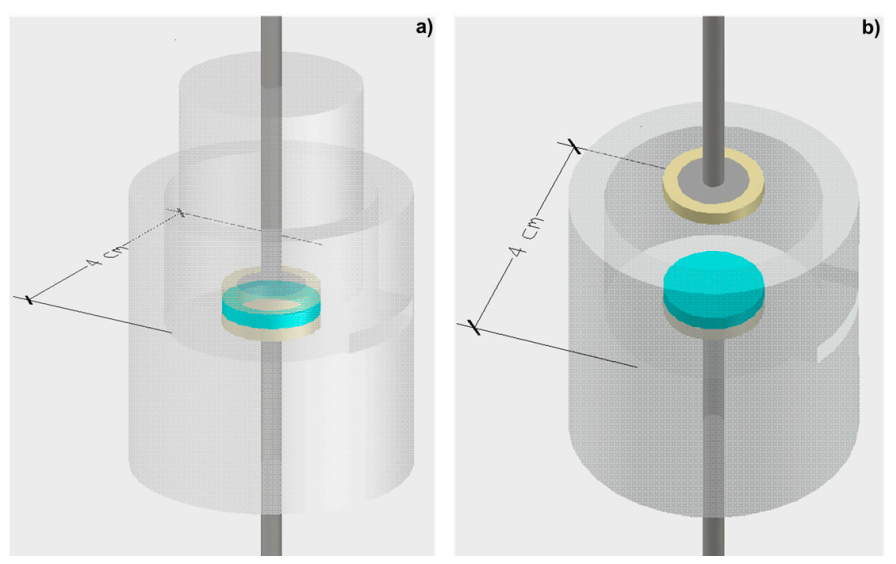

Figure 2. (a) Image of the support cell for Electrochemical Impedance Spectroscopy (EIS) measurements; and (b) top view of the cell. The blue disc represents the hybrid film that is placed between the two Au electrodes (adapted from [40]).

\subsection{Surface Characterization of the Hybrid Coatings Deposited on HDGS}

The morphology of the hybrid sol-gel coatings applied on HDGS specimens was studied by atomic force microscopy (AFM). The AFM images were taken operating in air using the dimension NanoScope III Controller Scanning mode in tapping mode (Veeco Instruments Inc., New York, NY, USA), before being immersed in the electrolyte (SCPS). The roughness of the HDGS substrate before and after applying one dip step of $\mathrm{U}(600), \mathrm{U}(900)$, and $\mathrm{U}(2000)$, and one and three dip steps of $\mathrm{U}(600): 3.45 T E O S$, $\mathrm{U}(900): 3.45 T E O S$ and U(2000):3.45TEOS were examined by AFM. 
2.8. Characterization of Corrosion Performance of Hybrid Coatings on HDGS Samples in Contact with SCPS by Open Circuit Potential and Polarization Resistance Measurements

The corrosion behavior of the HDGS coated samples with the different hybrid materials was studied in solutions simulating the concrete interstitial electrolyte (simulated concrete pore solutions (SCPS)) and contaminated with $1 \mathrm{wt}$. \% of chloride ions (SCPS $+1 \mathrm{wt} . \% \mathrm{Cl}^{-}$). SCPS were prepared according to the literature [41,42] by adding analytical reagent grades $0.2 \mathrm{M} \mathrm{KOH}$ to a $\mathrm{Ca}(\mathrm{OH})_{2}$ saturated solution previously prepared with distilled water. A final solution with a $\mathrm{pH}=13.2$ was obtained and after 8 days, $1 \mathrm{wt}$. $\%$ of chloride ions was added in the form of sodium chloride. This medium was prepared in order to induce the corrosion of the substrate. According to Moreno et al. [42], the critical chloride concentration reported to induce corrosion of reinforcing steel in SCPS, with pH values of 12.5 and 13.9, was of $0.02 \mathrm{wt}$. \% and $1 \mathrm{wt}$ \%, respectively. Since the $\mathrm{pH}$ of the SCPS used in this work was above 12.5, a value of $1 \mathrm{wt}$. \% was chosen to ensure that the chloride content was above the critical chloride concentration.

The corrosion behavior of the HDGS coated with the different hybrid materials was assessed by open circuit potential $(\mathrm{OCP})$ and polarization resistance $\left(\mathrm{R}_{\mathrm{p}}\right)$ measurements. All measurements were taken at room temperature. The measurements were performed with a three-electrode electrochemical cell (Figure 3) system using an established protocol [43-45]. The working electrode (WE) was a HDGS plate with an active area of $2 \mathrm{~cm}^{2}$ coated with the different hybrid materials. The counter electrode (CE) was a stainless steel (SS, type 316L) plate. The edges of both of the electrode plates, as well the non-active area and connecting zones, were protected with dual-component epoxy resin (Araldite ${ }^{\circledR}$ ). The set of two electrodes was fixed in plastic lids that fit in a $100 \mathrm{~mL}$ polyethylene flask (Normax) [43]. A titanium wire $\left(\mathrm{Ti} / \mathrm{TiO}_{2}\right)$ with a length of about one centimeter was used as reference electrode (REF) $[43,46]$. The electrodes were connected to an isolated copper cable and the cutting zone of the tip of the titanium electrode was covered with epoxy resin (Araldite ${ }^{\circledR}$ ). For comparison purposes, cells with non-coated HDGS WE electrodes were prepared and used as a reference, hereafter referred generically as control.

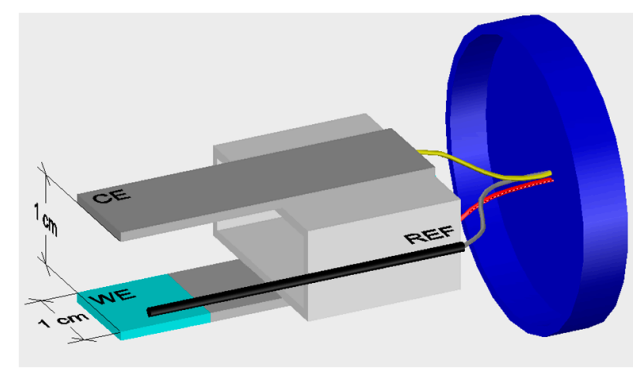

Figure 3. Electrochemical cell for polarization resistance measurements: WE, coated HDGS with the different hybrid materials; $\mathrm{CE}$, stainless steel; $\mathrm{REF}$, $\mathrm{Ti} / \mathrm{TiO}_{2}$ (adapted from [43]).

The $R_{p}$ values were estimated by the potentiostatic method using a potentiostat/galvanostat (Voltalab PGZ 301, (Radiometer Analytical-Hach Company, Loveland, CO, USA)). A small anodic potential pulse ( $\triangle \mathrm{E}=+10 \mathrm{mV}$ vs. reference electrode) was applied during $100 \mathrm{~s}$, starting from open circuit potential values. The current vs. time transient was recorded and the ohmic drop was calculated and then subtracted from the measured $R_{p}$ value $[44,45,47]$.

\section{Results and Discussion}

\subsection{NMR Analysis}

Structural features of the hybrid materials were investigated by multinuclear solid state NMR. The ${ }^{13} \mathrm{C}$ CPMAS spectra of the hybrid samples with and without TEOS are shown in Figure 4 and the assignments of the signals are reported in Table 2. 


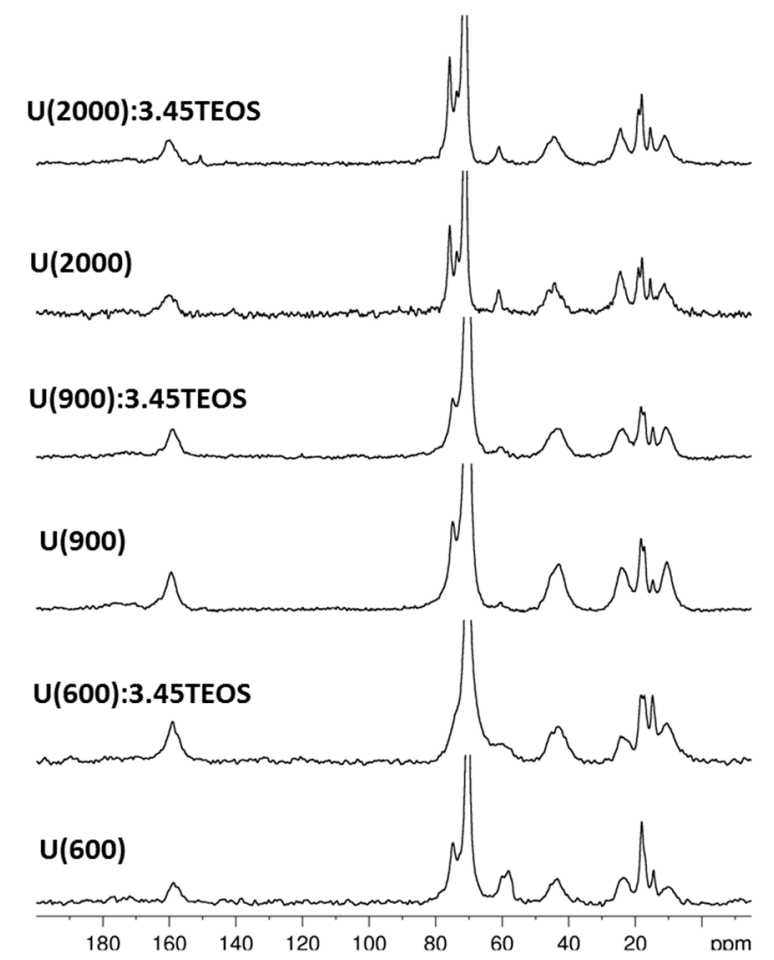

Figure 4. ${ }^{13} \mathrm{C}$ CPMAS spectra of hybrid samples with and without TEOS addition.

Table 2. ${ }^{13} \mathrm{C}-\mathrm{NMR}$ chemical shifts $(\delta(\mathrm{ppm}))$ and assignments based on literature [48-51].

\begin{tabular}{|c|c|}
\hline$\delta($ ppm) & Assignment \\
\hline 11.6 & $\mathrm{Si}-\mathrm{CH}_{2}$ (ICPTES) \\
\hline 15.7 & $\mathrm{CH}_{3} \cdot \mathrm{PPG}\left(\right.$ Jeffamine $\left.^{\circledR}\right)$ \\
\hline 18.0 & $\mathrm{CH}_{3} \cdot$ terminal PPG (Jeffamine ${ }^{\circledR}$ ) \\
\hline 20.0 & $\mathrm{CH}_{3} \cdot \mathrm{OEt}(\mathrm{ICPTES})$ \\
\hline 24.7 & $\mathrm{CH}_{2}$, propyl chain (Jeffamine ${ }^{\circledR}$ ) \\
\hline $44-46$ & $\mathrm{~N}-\mathrm{CH}_{2} / \mathrm{NCH}$ (ICPTES) \\
\hline 61.0 & $\mathrm{CH}_{2} \cdot \mathrm{OEt}(\mathrm{ICPTES})$ \\
\hline 70.4 & $\mathrm{OCH}_{2} \cdot \mathrm{PEG}\left(\right.$ Jeffamine $\left.^{\circledR}\right)$ \\
\hline $72-76$ & $\mathrm{OCH} \cdot \mathrm{OCH}_{2} \cdot \mathrm{PPG}\left(\right.$ Jeffamine $\left.^{\circledR}\right)$ \\
\hline 124.8 & $\mathrm{~N}=\mathrm{C}=\mathrm{O}(\mathrm{ICPTES})$ \\
\hline 160.2 & $\mathrm{C}=\mathrm{O}(\mathrm{HN}-\mathrm{CO}-\mathrm{NH} / \mathrm{NH}-\mathrm{COO}$-bridge, hybrid $)$ \\
\hline
\end{tabular}

The final materials give rise to carbon spectra characterized by sharp peaks due to the mobile PPG/PEG chains of the Jeffamine ${ }^{\circledR}$ molecules and broad peaks produced by the short organic chains and the unreacted alkoxide groups of the silane. The spectra of samples with and without TEOS result superimposable, suggesting the hydrolysis of the ethoxide groups belonging to the tetra-alkoxysilane. Figure 5 reports the comparison among the spectra of Jeffamine ${ }^{\circledR} 2000$, ICPTES and the corresponding hybrid sample (U(2000)); since the pristine reagents are liquid, a small shift with respect to their signals in the solid state is expected. In the ICPTES spectrum, the peak attributed to the carbon atom in the isocyanate group $(-\mathrm{N}=\mathrm{C}=\mathrm{O})$ is found at approximately $125 \mathrm{ppm}$. In the spectrum of the hybrid sample (U(2000) (Figure 6), the absence of the $\mathrm{N}=\mathrm{C}=\mathrm{O}$ ICPTES peak and the broad signal at about $160 \mathrm{ppm}$ clearly shows that the reaction between the polymer amino groups and the $\mathrm{N}=\mathrm{C}=\mathrm{O}$ end group of ICPTES took place. 


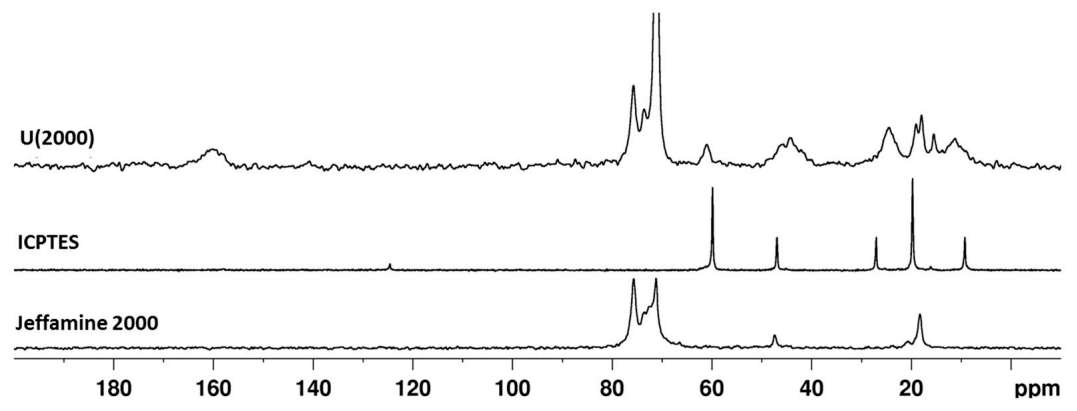

Figure 5. ${ }^{13} \mathrm{C}$ CPMAS spectra of hybrid sample U(2000) 1:4.16 and pure reagents (ICPTES and Jeffamine ${ }^{\circledR}$ 2000).

Nevertheless, the broad resonance at 160 ppm cannot be attributed to a single component but appears to be the result of several overlapped signals. According to the molar ratio among the reagents (Table 1), the amount of isocyanate groups is over-stoichiometric with respect to the Jeffamine terminal $\mathrm{NH}_{2}$ groups and, potentially, only half of the $\mathrm{N}=\mathrm{C}=\mathrm{O}$ groups can react with the amino groups of the Jeffamine molecule. Therefore, the residual isocyanate groups may react with ethanol leading to the formation of the urethane function. For assessing this hypothesis, ICPTES and Jeffamine ${ }^{\circledR} 600$ (selected according to the lower viscosity) have been mixed in the NMR tube in 1:4.16 molar ratios with deuterated ethanol and the ${ }^{13} \mathrm{C}-\mathrm{NMR}$ spectra have been acquired on the solution just after mixing the reagents, after $24 \mathrm{~h}$ aging and with the addition of citric acid (Figure S1, Supplementary Materials).

The ${ }^{13} \mathrm{C}-\mathrm{NMR}$ spectrum, recorded on the mixture immediately after mixing, shows a signal at $159 \mathrm{ppm}$ and a less intense resonance at $157 \mathrm{ppm}$, respectively attributed to the $-\mathrm{HNCONH}-$ and -HNCOO-bridges $[51,52]$ formed by reaction of the isocyanate groups of ICPTES. After $24 \mathrm{~h}$, the decrease in intensity of the peak at $123 \mathrm{ppm}$ due to $\mathrm{N}=\mathrm{C}=\mathrm{O}$ is clear, and the two resonances at 159 and $157 \mathrm{ppm}$ present similar intensity. From these results, it can be concluded that both urea and urethane bridges are immediately created after the mixing of reagents. However, the formation of the -HNCONH- bridge is favored. It should be noted that the stoichiometric conditions used here caused the formation, during the aging process, of a valuable amount of urethane functions. The stability of the formed urea and urethane bridges has been evaluated by adding citric acid to the aged mixture. The carboxylic acid addition leads to the appearance in the spectrum of the carboxy groups signals at 170.4, 172.6 and $175.6 \mathrm{ppm}$, but does not affect the -HNCONH- and -HNCOO- signals, since the only variation is the increase of urethane groups by further isocyanate group consumption.

The quantitative analysis of the carbonyl band in the solid state ${ }^{13} \mathrm{C}$ spectra of hybrid samples (Figure 4) is limited by the unsatisfactory signal-to-noise ratio (S/N). In order to better point out the signal components in the range $150-170 \mathrm{ppm}$ (Figure 4), a ${ }^{13} \mathrm{C}$ CPMAS spectrum was recorded on a selected sample with very high number of scans (10 k scans) and the profile fitting analysis was performed on the low-field part of the spectrum which presents more resolved signals and improved S/N (Figure S2, Supplementary Materials). The carbonyl band appears to be the result of four overlapping signals, two intense resonances at $159 \mathrm{ppm}(47 \%)$ and $157 \mathrm{ppm} \mathrm{(26 \% )}$ and two signals at $154(16 \%)$ and $162 \mathrm{ppm}(11 \%)$. The clear assignment of the latter components is still under investigation but, in agreement with a previous FTIR study pointing out the presence of several components in the amide band of ureasilicate samples [53], that may be related to chains with different hydrogen bonding interactions.

A weak and broad resonance is also detected at about 172 ppm (Figure S2, Supplementary Materials), which can be attributed to the carboxylate functions of citric acid in agreement with the NMR study in solution (Figure S1, Supplementary Materials). The ${ }^{13} \mathrm{C}$ spectra of hybrid samples (Figure 4 and Table 2) reveal the signals of residual ethoxyde groups suggesting that the organosilane hydrolysis is not complete in spite of the hydrolysis ratio used in the hybrid synthesis (Table 1). The content of citric acid in the mixtures is about $10 \%$ with respect to the whole silane amount 
(Table 1) and the complexation of the Si units by citric acid cannot be excluded, taking into account the well-known reactivity of carboxylic acids towards silicon alkoxides [54].

In the hybrid samples (Figure 4), the signals of PEG/PPG moieties appear unchanged when compared to the pristine Jeffamine ${ }^{\circledR}$ molecules. The only exception is with Jeffamine ${ }^{\circledR} 2000$. The resonances at around 70-75 ppm change both in shape and intensity, when comparing the spectra of Jeffamine 2000 and U(2000) (Figure 5). Since these signals are not related to reactive parts of the molecules, the conformation rearrangement of the chains in the hybrid could be responsible for peak changes. Previous observations on the evolution of the FTIR signal of oxyethylene chains [53] pointed out that, in the hybrids, the chains partially lose the original helical conformation, acquiring a less ordered structure.

The ${ }^{29}$ Si NMR spectra were recorded on hybrid samples using both CP (Figure S3, Supplementary Materials) and SP (Figure 6) sequences; the Si units are labeled using the common NMR notation: $\mathrm{Q}^{\mathrm{n}}$ and $\mathrm{T}^{\mathrm{n}}$ are tetrafunctional $\mathrm{SiO}_{4}$ and trifunctional $\mathrm{SiCO}_{3}$ units, respectively and $\mathrm{n}$ is the number of siloxane bridges. The results of the profile fitting analysis of the ${ }^{29} \mathrm{Si}$ MAS NMR spectra are reported in Table 3.

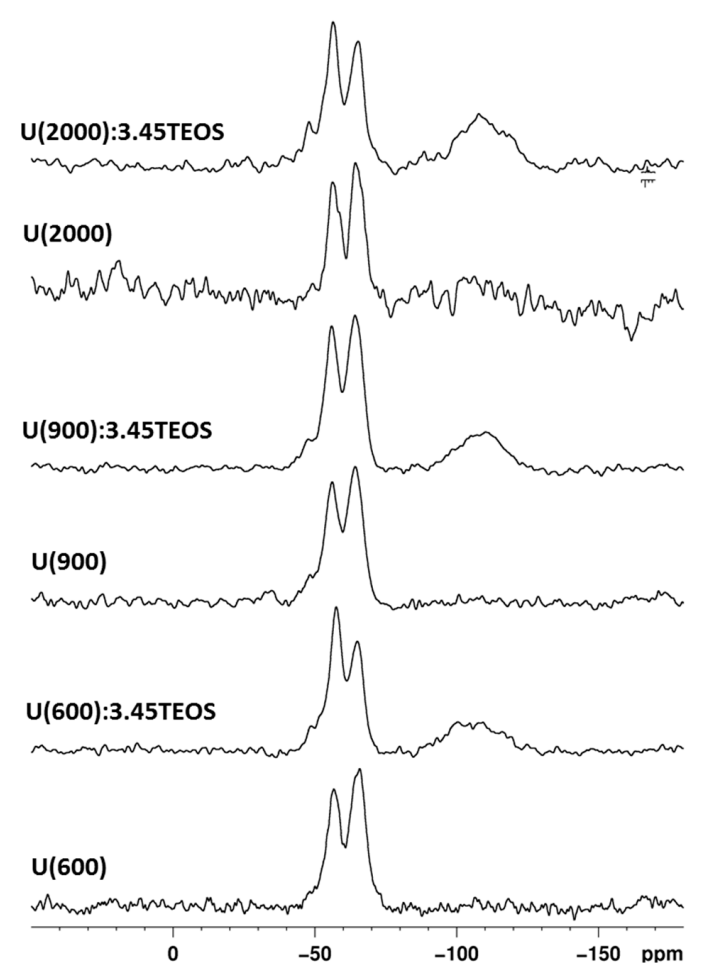

Figure 6. ${ }^{29}$ Si MAS NMR spectra of hybrid samples prepared with and without TEOS.

The ${ }^{29} \mathrm{Si}$ NMR spectra (Figure 6) shows the typical signals of T units $(-50 \div-70 \mathrm{ppm})$ due to ICPTES, and $Q$ units $(-90 \div-120 \mathrm{ppm})$ for samples prepared with TEOS addition. Hybrid samples prepared without TEOS addition show only $\mathrm{T}^{2}$ and $\mathrm{T}^{3}$ species. The degree of condensation (DOC) calculated according to the following equation [55]:

$$
\mathrm{DOC}=\frac{\left(\mathrm{T}^{1}+2 \mathrm{~T}^{2}+3 \mathrm{~T}^{3}+2 \mathrm{Q}^{2}+3 \mathrm{Q}^{3}+4 \mathrm{Q}^{4}\right)}{3\left(\mathrm{~T}^{1}+\mathrm{T}^{2}+\mathrm{T}^{3}\right)+4\left(\mathrm{Q}^{2}+\mathrm{Q}^{3}+\mathrm{Q}^{4}\right)}
$$

is around $85 \%$ (Table 3). With TEOS addition, the $\mathrm{T}$ region is characterized by the signals of $\mathrm{T}^{1}$, $\mathrm{T}^{2}$, and $\mathrm{T}^{3}$ units, and the $\mathrm{Q}$ region presents the signals of $\mathrm{Q}^{2}, \mathrm{Q}^{3}$ and $\mathrm{Q}^{4}$ units; generally, the DOC values are very similar to those of the samples prepared without TEOS (Table 3 ). The ${ }^{29} \mathrm{Si} \mathrm{NMR}$ study 
confirms the reduced extent of hydrolysis-condensation of the sol-gel network as suggested by the ${ }^{13}$ C-NMR spectra.

Table 3. ${ }^{29} \mathrm{Si}$ NMR chemical shifts, assignments and relative amounts of silicon species (values are reported with a $95 \%$ confidence level).

\begin{tabular}{cccccccccc}
\hline Si Unit & $\mathbf{T}^{\mathbf{1}}$ & $\mathbf{T}^{\mathbf{2}}$ & $\mathbf{T}^{\mathbf{3}}$ & $\mathbf{Q}^{\mathbf{2}}$ & $\mathbf{Q}^{\mathbf{3}}$ & $\mathbf{Q}^{\mathbf{4}}$ & $\mathbf{D O C}$ & $\mathbf{\%} \mathbf{Q}$ & $\mathbf{Q} / \mathbf{T}$ \\
\hline$\delta(\mathrm{ppm})$ & -49.5 & -56.9 & -64.4 & -89.5 & -99.3 & -110.0 & - & - & - \\
$\mathrm{U}(600)$ & 7.6 & 36.4 & 56.0 & - & - & - & 82.8 & 100.0 & - \\
$\mathrm{U}(600): 3.45 T E O S$ & 5.7 & 36.7 & 32.0 & - & 15.9 & 9.6 & 80.3 & 74.5 & 0.3 \\
$\mathrm{U}(900)$ & 9.6 & 38.8 & 51.6 & - & - & - & 80.7 & 100.0 & - \\
$\mathrm{U}(900): 3.45 T E O S$ & 6.9 & 29.4 & 39.5 & - & 5.2 & 18.9 & 85.0 & 75.9 & 0.4 \\
$\mathrm{U}(2000)$ & & 42.1 & 57.9 & - & - & - & 86.0 & 100.0 & - \\
$\mathrm{U}(2000): 3.45 T E O S$ & 3.6 & 27.7 & 32.9 & 7.2 & 12.5 & 16.0 & 81.6 & 64.3 & 0.6 \\
\hline
\end{tabular}

The Q/T ratio reported in Table 3 assesses the amount of TEOS incorporated into the hybrid networks. The calculated values are different from the nominal ones; only the sample prepared with high MW of Jeffamine ${ }^{\circledR}$ shows an amount of $Q$ units closer to the expected value (Q/T 0.8). In order to prove that the $\mathrm{Q}$ units were not underestimated as a consequence of the MAS experiment conditions, these results were validated acquiring the MAS spectra with increasing the relaxation time parameter.

Besides the Q/T ratio obtained by the quantitative analysis, the $Q$ units are not clearly visible in the ${ }^{29} \mathrm{Si}$ CPMAS spectra (Figure S3, Supplementary Materials), contrariwise to CP spectra usually recorded with the same parameters on sol-gel hybrid organic/inorganic samples [55]. Work is in progress to clarify this result, which indicates poor magnetization transfer efficiency in the CP experiments, resulting from large distances among protons and TEOS-derived units in the network. One possible explanation could be the segregation of $Q$ domains as a consequence of TEOS complexation with citric acid. The resulting silicate units would belong to the $Q$ units region but contribute to creating the large quantity of $\mathrm{Q}^{3}$ and $\mathrm{Q}^{2}$ units, thus decreasing the overall DOC (Table 3).

\subsection{Glow Discharge Optical Emission Spectroscopy (GD-OES)}

GD-OES was used to obtain quantitative composition profiles in order to investigate the thickness of the hybrid coatings as a function of the number of layers deposited. The depth profiling chemical composition of every coating applied on HDGS was determined by GD-OES according to ISO 16962:2005(E). The detected elements were $\mathrm{Zn}, \mathrm{Fe}, \mathrm{Si}$ and C. The hybrid thickness was obtained from the difference between the depth found for the coated sample (zinc layer depth + the hybrid depth) and the uncoated sample (zinc layer depth). Table 4 shows the depth profile obtained for all samples studied.

GD-OES results show that Si was detected in a range of 21 to $30 \mu \mathrm{m}$ of coating depth (Table 4). The thickness of the hybrid coatings was in a range between 2 to $11 \mu \mathrm{m}$. With exception of $U(2000): 3.45$, Table 2 shows that, compared to the deposition of one layer, the coating thickness duplicates when three layers are deposited.

Table 4. Depth of the hybrid coating and zinc layer and thicknesses obtained for each sample.

\begin{tabular}{|c|c|c|c|c|}
\hline Samples & $\begin{array}{l}\text { Number of } \\
\text { Layers }\end{array}$ & 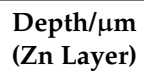 & $\begin{array}{c}\text { Depth } \mathrm{a} / \mu \mathrm{m} \\
\text { (Hybrid }+\mathrm{Zn} \text { Layer) }\end{array}$ & $\begin{array}{c}\text { Hybrid Thickness } / \mu \mathrm{m} \\
\text { (Hybrid + Zn Layer }- \text { Zn Layer) }\end{array}$ \\
\hline Control & - & 19 & - & - \\
\hline \multirow[t]{2}{*}{$\mathrm{U}(600): 3.45 \mathrm{TEOS}$} & 1 & - & 21 & 2 \\
\hline & 3 & & 25 & 4 \\
\hline \multirow[t]{2}{*}{$\mathrm{U}(900): 3.45 \mathrm{TEOS}$} & 1 & - & 23 & 4 \\
\hline & 3 & & 27 & 8 \\
\hline \multirow{2}{*}{$\mathrm{U}(2000): 3.45$ TEOS } & 1 & - & 28 & 9 \\
\hline & 3 & & 30 & 11 \\
\hline
\end{tabular}

${ }^{a}$ Hybrid thickness obtained according to ISO 16962:2005(E). 


\subsection{Electrochemical Impedance Spectroscopy (EIS) Analysis}

Figure 7 shows the Nyquist complex impedance plots obtained from the EIS analysis of the film samples, namely $\mathrm{U}(600), \mathrm{U}(900)$ and $\mathrm{U}(2000)$ synthesized with a molar ratio of Jeffamine:ICPTES equal to 1:4.16. The electrical equivalent circuit (EEC) used to describe the observed impedance response of each hybrid is shown as an inset in each Nyquist plot.

Figure 8 shows representative examples of the Nyquist plots obtained for $U(X)$ samples enriched with different ratios of TEOS, namely U(600):3.45TEOS, U(900):3.45TEOS and U(2000):3.45TEOS.
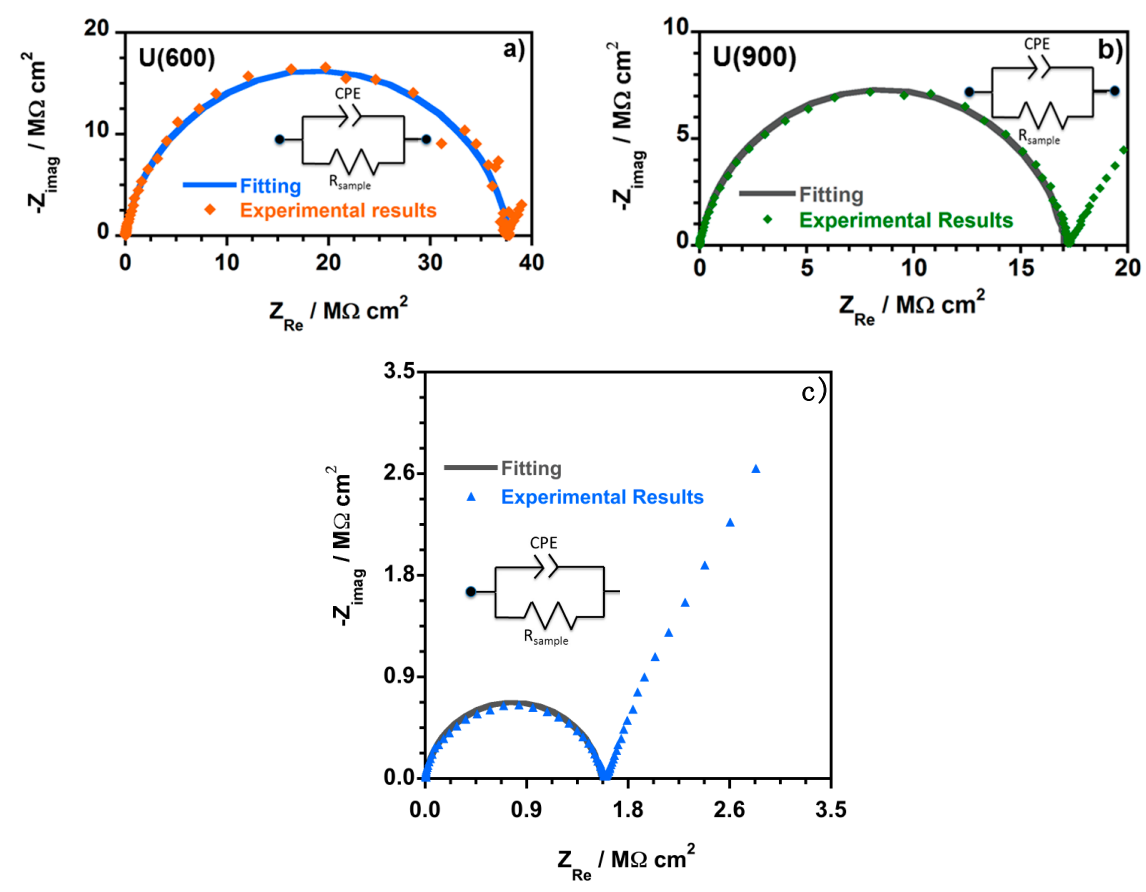

Figure 7. Typical complex plane impedance plots and the respective fitting obtained for hybrid films: (a) U(600); (b) U(900); and (c) U(2000) prepared with a molar ratio of Jeffamine:ICPTES = 1:4.16 (with the EEC as inset used to analyze the EIS response).
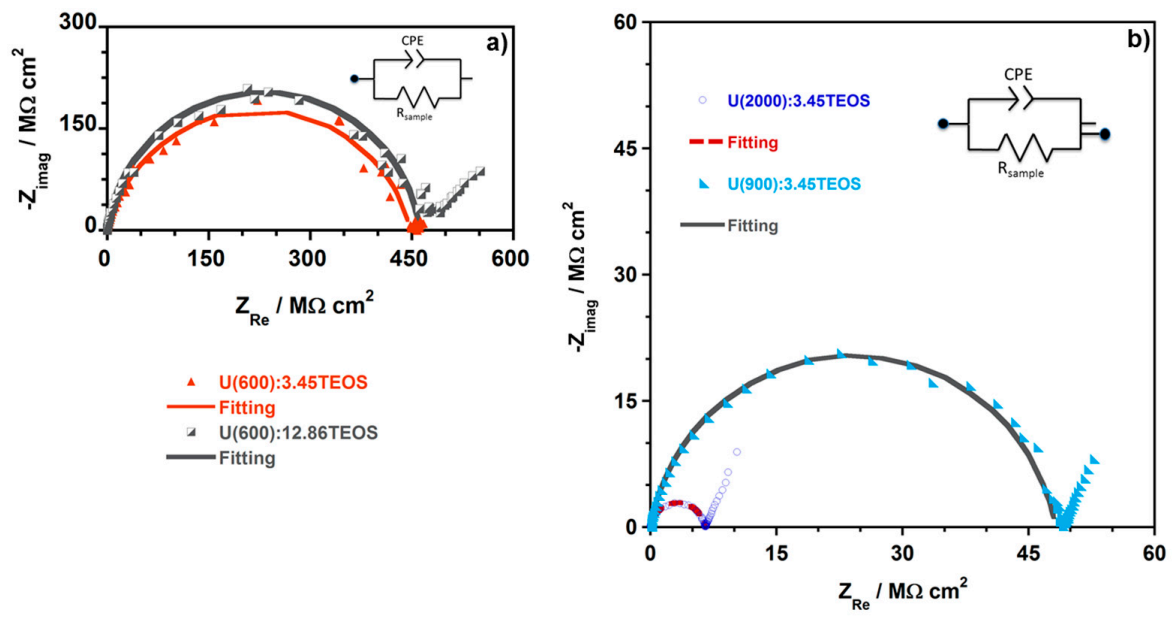

Figure 8. Typical complex plane impedance plots and the respective fitting obtained for hybrid films prepared with a molar ratio of Jeffamine:ICPTES = 1:4.16 and enriched with TEOS: (a) U(600):3.45TEOS and U(600):12.86TEOS; and (b) U(900):3.45TEOS and U(2000):3.45TEOS. The EECs used to analyze the EIS response are inset. 
Figures 7 and 8 show that, at higher frequencies, a semicircle that intercepts the $x$-axis is present in all the Nyquist plots. The amplitude of the semi-circles changes with the sample composition. This is assigned to the electric properties, such as conductivity and capacitance, of the hybrid films. Data obtained at lower frequencies describe a line suggesting another electrochemical process, which is attributed to the $\mathrm{Au} \mid$ hybrid film interface [32]. The semicircles in the Nyquist plots (Figures 7 and 8) show a depressed form, and so the analysis of all the impedance responses was based on EEC where constant phase elements (CPE) were used instead of pure capacitance. The impedance of a $\mathrm{CPE}$ is known by [56]:

$$
\mathrm{Z}_{\mathrm{CPE}}=1 /\left[\mathrm{Q}(\mathrm{j} \omega)^{\alpha}\right]
$$

where $\alpha$ and $Q$ represent parameters regardless of the frequency [57]. When $\alpha=1, Q$ represents the capacity $\left(\mathrm{F} / \mathrm{cm}^{2}\right)$ while if $\alpha \neq 1$, Q has units of $\mathrm{S}^{\alpha} / \Omega \mathrm{cm}^{2}$ and the system shows a behavior that is linked to the surface heterogeneity [57-59].

A resistive-capacitive parallel circuit was considered and the impedance for the EEC is given by [57]:

$$
\mathrm{Z}_{\mathrm{CPE}}=\mathrm{R}_{\text {Sample }} /\left[1+(\mathrm{j} \omega)^{\alpha} \mathrm{QR}_{\text {Sample }}\right]
$$

$\mathrm{R}_{\text {Sample }}$ represents the resistance in parallel with the CPE. The CPE parameter $\mathrm{Q}$ cannot be equated to the interfacial capacitance $\left(\mathrm{C}_{\text {eff }}\right)$. Therefore, the $\mathrm{C}_{\text {eff }}$ was estimated using the relationship developed by Brug et al. $[57,58]$ :

$$
\mathrm{C}_{\text {eff }}=\left[\mathrm{QR}_{\text {sample }}{ }^{(1-\alpha)}\right]^{1 / \alpha}
$$

$C_{\text {eff }}$ values were calculated according to Equation (4). Normalized resistance $\left(R / \Omega \cdot \mathrm{cm}^{2}\right)$, normalized capacitance $\left(\mathrm{C} / \mathrm{nF} \cdot \mathrm{cm}^{-2}\right)$ and conductivity $\left(\sigma / \mathrm{S} \cdot \mathrm{cm}^{-1}\right)$ were also determined. The $R$ and $C$ values were normalized to cell geometry dimensions. The obtained values were calculated using the following equations (where $\mathrm{A}_{\mathrm{Au}}$ is the area of the gold electrodes and $\mathrm{d}_{\text {Sample }}$ the thickness of the analyzed OIH film sample).

$$
\begin{gathered}
\mathrm{R}=\mathrm{R}_{\text {Sample }} \times \mathrm{A}_{\text {Au disc }} \\
\mathrm{C}=\mathrm{C}_{\text {eff }} / \mathrm{A}_{\text {Au disc }} \\
\sigma=\left(\mathrm{d}_{\text {Sample }} / \mathrm{A}_{\text {Au disc }}\right) / \mathrm{R}_{\text {Sample }} \\
\varepsilon_{\mathrm{r}}=\left(\mathrm{C}_{\mathrm{eff}} \times \mathrm{d}_{\text {Sample }}\right) / \varepsilon_{\mathrm{o}} \times \mathrm{A}_{\text {Au disc }}
\end{gathered}
$$

Only the electrochemical process at high frequencies was fitted and the EEC used to model the Nyquist plots for all the hybrid contain a simple CPE $\left(\mathrm{Q} / \mathrm{S}^{\alpha} \Omega^{-1} \cdot \mathrm{cm}^{-2}\right)$ and a Resistance $\left(\mathrm{R}_{\text {sample }} / \Omega \cdot \mathrm{cm}^{2}\right)$, which is associated to the hybrid film resistance. Five measurements were performed for each hybrid sample. However, only one representative example among the five measurements performed is shown (Table 5). The obtained fitting parameters, namely $R_{\text {Sample }}, Q$ (represented by CPE in the EEC) and $\alpha$ as well as the percentage of error associated to each element are presented in Table 5 . The data obtained at lower applied frequencies describe a line suggesting another electrochemical process. This process is assigned to Au I hybrid film interfacial phenomena and a simple R-C EEC describes this part of the Nyquist plot. However, the fitting was not executed since it was not relevant for the understanding of the electrochemical behavior of hybrid films. The solid lines in all the Nyquist plots correspond to the fitted regions. The behavior observed at the different frequency ranges is a consequence of capacitance time constants with large differences that are linked to the charge transport across the hybrid and the charge relaxation that occurs at the interfaces.

$\mathrm{C}_{\text {eff }}$ values were calculated according to Equation (4) and as described in previous publications $[32,36,60]$. The resistance $(R)$ and capacitance $(C)$ values were normalized to cell geometry dimensions. The conductivity $\left(\sigma / \mathrm{S} \cdot \mathrm{cm}^{-1}\right)$ was also determined. 
Table 5. EIS data fitting of the $\mathrm{U}(\mathrm{X})$ hybrid film samples with different ratios of TEOS.

\begin{tabular}{ccccc}
\hline Hybrid Sample & $\mathbf{R}_{\text {Sample }} / \mathbf{\Omega} \cdot \mathbf{c m}^{\mathbf{2}}$ & $\mathbf{C P E}(\mathbf{Q}) / \mathbf{S}^{\boldsymbol{\alpha}} \cdot \mathbf{\Omega}^{-\mathbf{1}} \cdot \mathbf{c m}^{-\mathbf{2}}$ & $\boldsymbol{\alpha}$ & $\mathbf{X}^{\mathbf{2}}$ \\
\hline $\mathrm{U}(600)$ & & & & \\
\hline $1: 4.16: 0^{\text {(a) }}$ & $3.78 \times 10^{7}( \pm 0.85 \%)$ & $1.42 \times 10^{-11}( \pm 3.14 \%)$ & $0.90( \pm 0.29 \%)$ & $7.09 \times 10^{-3}$ \\
$1: 4.16: 3.45^{\text {(a) }}$ & $4.48 \times 10^{8}( \pm 3.71 \%)$ & $1.59 \times 10^{-11}( \pm 3.71 \%)$ & $0.85( \pm 0.47 \%)$ & $7.47 \times 10^{-3}$ \\
$1: 4.16: 4.29$ & $3.15 \times 10^{8}( \pm 1.30 \%)$ & $2.75 \times 10^{-11}( \pm 3.06 \%)$ & $0.90( \pm 0.32 \%)$ & $2.30 \times 10^{-2}$ \\
$1: 4.16: 12.86^{\text {(a) }}$ & $9.42 \times 10^{5}( \pm 0.19 \%)$ & $3.92 \times 10^{-10}( \pm 3.23 \%)$ & $0.76( \pm 0.40 \%)$ & $1.64 \times 10^{-2}$ \\
\hline $\mathrm{U}(900)$ & & & \\
\hline $1: 4.16: 0^{\text {(a) }}$ & $1.71 \times 10^{7}( \pm 0.72 \%)$ & $4.36 \times 10^{-11}( \pm 3.14 \%)$ & $0.90( \pm 0.31 \%)$ & $1.05 \times 10^{-2}$ \\
$1: 4.16: 3.45^{\text {(a) }}$ & $4.82 \times 10^{7}( \pm 1.14 \%)$ & $1.61 \times 10^{-11}( \pm 3.91 \%)$ & $0.89( \pm 0.41 \%)$ & $9.95 \times 10^{-3}$ \\
\hline $\mathrm{U}^{2}(2000)$ & & & \\
\hline $1: 4.16: 0^{\text {(a) }}$ & $1.52 \times 10^{6}( \pm 0.59 \%)$ & $5.98 \times 10^{-11}( \pm 4.30 \%)$ & $0.91( \pm 0.42 \%)$ & $7.23 \times 10^{-3}$ \\
$1: 4.16: 3.45^{\text {(a) }}$ & $6.50 \times 10^{6}( \pm 0.44 \%)$ & $2.32 \times 10^{-11}( \pm 2.68 \%)$ & $0.93( \pm 0.24 \%)$ & $3.92 \times 10^{-3}$ \\
\hline
\end{tabular}

Notes: (a) EIS data fitting at high frequencies using the EEC, as shown as inset in correspondent Nyquist plots, Figures 7 and 8.

Table 6, shows the average values of the logarithm of resistance $(\log R)$, conductivity $(-\log \sigma), C$ and $\varepsilon_{\mathrm{r}}$ obtained for all the samples of each hybrid film (uncertainty is expressed for $95 \%$ confidence). Figure 9 shows the average values of the conductivity $(-\log \sigma)$ (uncertainty is expressed for $95 \%$ confidence, (Table 6)) obtained for the hybrid film samples prepared with Jeffamine with a MW of approximately $600 \mathrm{~g} \cdot \mathrm{mol}^{-1}$ with different contents of TEOS (according to Table 1).

The conductivity values obtained for the $U(X)$ samples prepared with a molar ratio of Jeffamine:ICPTES $=1: 4.16$ are lower when compared to the data obtained for samples prepared with a molar ratio of Jeffamine:ICPTES $=1: 2$ [32]. When TEOS is added, Table 6 and Figure 9 show that, as the content of TEOS increases, the conductivity keeps decreasing, the normalized $R$ values increase and the $\varepsilon_{\mathbf{r}}$ decreases. Moreover, excepting for the hybrid films based on $\mathrm{U}(2000)$ matrices, the normalized $R$ values obtained are all above $10^{7} \Omega \cdot \mathrm{cm}^{2}$ (Table 5), suggesting that these materials meet the necessary requirements to provide an effective corrosion protection [61,62].

Table 6. Electrical properties (average values) obtained for the $U(X)$ hybrid film samples with different ratios of TEOS.

\begin{tabular}{ccccc}
\hline Hybrid Sample & $\log \left(\mathbf{R} / \Omega \cdot \mathbf{c m}^{2}\right)$ & $-\log \left(\sigma / \mathbf{S c m}^{-1}\right)$ & $\mathrm{C} / \mathbf{p F} \cdot \mathbf{c m}^{-2}$ & $\varepsilon_{\mathbf{r}}$ \\
\hline $\mathrm{U}(600)$ & & & & \\
$1: 4.16: 0$ & $7.47 \pm 0.01$ & $8.31 \pm 0.01$ & $8.12 \pm 0.05$ & $13.4 \pm 0.1$ \\
$1: 4.16: 3.45$ & $8.57 \pm 0.03$ & $9.86 \pm 0.03$ & $8.69 \pm 0.42$ & $15.8 \pm 0.8$ \\
$1: 4.16: 4.29$ & $8.41 \pm 0.06$ & $9.92 \pm 0.06$ & $20.5 \pm 2.0$ & $9.40 \pm 1.10$ \\
$1: 4.16: 12.86$ & $8.56 \pm 0.04$ & $10.5 \pm 0.1$ & $30.8 \pm 0.6$ & $3.70 \pm 0.10$ \\
$\mathrm{U}(900)$ & & & & \\
$1: 4.16: 0$ & $7.16 \pm 0.06$ & $8.20 \pm 0.03$ & $25.1 \pm 0.1$ & $23.9 \pm 0.1$ \\
$1: 4.16: 3.45$ & $7.57 \pm 0.02$ & $8.50 \pm 0.02$ & $8.80 \pm 0.07$ & $11.6 \pm 0.4$ \\
$\mathrm{U}(2000)$ & & & & \\
$1: 4.16: 0$ & $6.13 \pm 0.09$ & $7.20 \pm 0.16$ & $31.0 \pm 3.5$ & $29.7 \pm 1.9$ \\
$1: 4.16: 3.45$ & $6.67 \pm 0.11$ & $7.65 \pm 0.04$ & $14.1 \pm 0.2$ & $15.3 \pm 0.2$ \\
\hline
\end{tabular}

The results show that the addition of TEOS to the hybrid matrices, which increases the inorganic component of the matrix and decreases the sol viscosity, improves the barrier properties of the ureasilicate matrices by increasing their resistance (and decreasing the conductivity); this evidence is in agreement with previous studies [31,37].

The capacitance is another parameter used for the characterization of the barrier protective properties. The values obtained for samples based on U(600) matrices (Table 5) generally increase when the content of TEOS increases. However, for higher MWs of Jeffamine ${ }^{\circledR}$ this tendency was not found. Samples based on U(900) and U(2000) matrices showed lower capacitances when the content 
of TEOS increased. EIS data evidence that the molecular size of organic (Jeffamine ${ }^{\circledR}$ ) component in the ureasilicate network has a major relevance on the dielectric properties. This emphasizes that the charge transport and relaxation processes occur predominantly across in the organic environment.

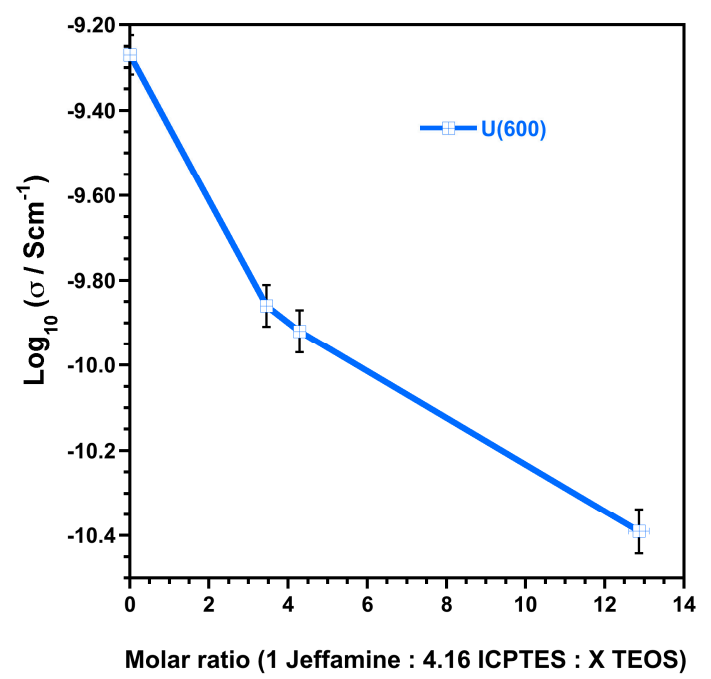

Figure 9. Average values of conductivity obtained at room temperature for U(600) film matrices prepared with different ratios of TEOS using a molar ratio of Jeffamine:ICPTES = 1:4.16.

\subsection{Atomic Force Microscopy (AFM)}

The AFM analysis of the surface of HDGS coated samples were scanned on an area of $10 \times 10 \mu \mathrm{m}^{2}$. Figure 10 shows representative topographic images of samples coated with one layer of hybrid enriched with TEOS before immersion in SCPS.

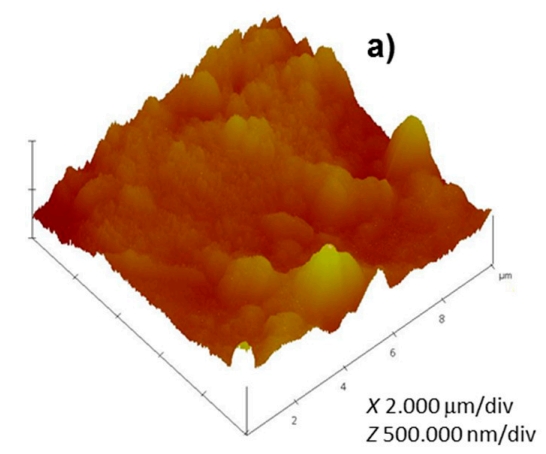

c)

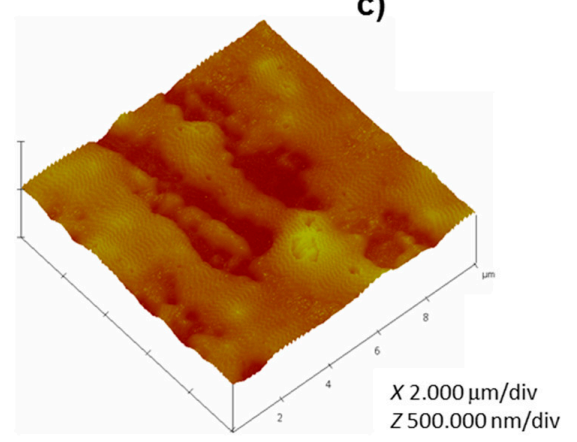

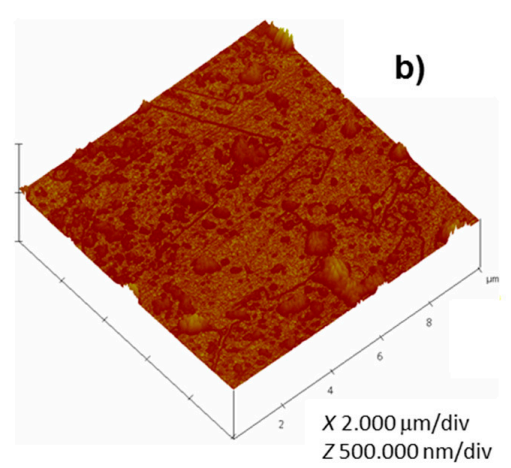

d)

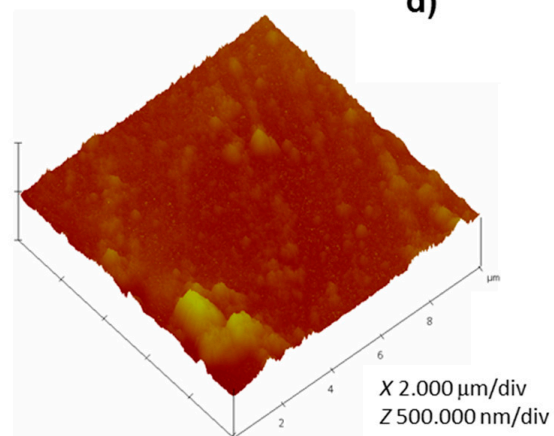

Figure 10. Atomic Force microscopy (AFM) topographic images (3D view) for: (a) control (uncoated HDGS); and HDGS samples coated with one layer of: (b) U(600):3.45TEOS; (c) U(900):3.45TEOS; and (d) U(2000):3.45TEOS. 
As expected, coated samples displayed smoother surfaces compared to control (uncoated samples). Nevertheless, the coated surfaces were not uniform and the presence of defects was also detected (Figure 10). The coating method deposition used, as well as the curing process, may explain the presence of these agglomerates and defects $[27,33,34]$. The amplitude parameters used to characterize the topography of a surface are the average roughness $\left(R_{a}\right)$ and the root mean square roughness $\left(R_{q}\right)$. Table 6 shows the values of $R_{q}, R_{a}$, and $R_{\max }$ (maximum vertical distance between the highest and lowest data points within a given area) for the control and HDGS-coated samples. As expected, control shows higher $R_{\mathrm{q}}$ values (above $100 \mathrm{~nm}$ ) and coated samples show lower $R_{\mathrm{q}}$ values, below or equal to $46 \mathrm{~nm}$ for samples without TEOS and below or equal to $35 \mathrm{~nm}$ for samples enriched with TEOS.

Generally, Table 7 shows that, as the MW of Jeffamine ${ }^{\circledR}$ increases, the coating roughness $\left(R_{\mathrm{q}}\right)$ increases. The introduction of TEOS during the synthesis leads to coatings with lower $R_{q}$ values. This effect is due, probably, to the decrease of the viscosity of the sol hybrid sols by TEOS addition, which allows improved distribution on the metallic substrate.

$\mathrm{U}(900)$ samples are an exception, as the samples prepared with TEOS showed higher $R_{q}, R_{a}$ and $\mathrm{R}_{\mathrm{q}}$ than samples prepared without TEOS. It is worth of noting that $\mathrm{R}_{\max }$ obtained for samples prepared with Jeffamine ${ }^{\circledR}$ of MW 2000 is very high, when compared to other samples (generally $\approx 3$ times higher). Again this result can be related to the viscosity of the hybrid sols. Indeed, as the MW of Jeffamine ${ }^{\circledR}$ increases the viscosity of the sols increase. Accordingly, for samples prepared with Jeffamine ${ }^{\circledR}$ of $\mathrm{MW} \approx 2000 \mathrm{~g} \cdot \mathrm{mol}^{-1}$, the high viscosity results in inefficient/poor sol distribution and leads to the formation of large agglomerates (defects). These defects present higher dimensions than the ones formed when MWs of Jeffamine ${ }^{\circledR}$ are used.

Table 7. Roughness parameters obtained for control and the different coated HDGS samples coated with one layer.

\begin{tabular}{cccc}
\hline Sample & $\mathbf{R}_{\mathbf{q}} / \mathbf{n m}$ & $\mathbf{R}_{\mathbf{a}} / \mathbf{n m}$ & $\mathbf{R}_{\mathbf{m a x}} / \mathbf{n m}$ \\
\hline Uncoated HDGS & 107 & 82 & 611 \\
HDGS_U(600) 1 layer & 14 & 11 & 106 \\
HDG_U(600):3.45TEOS 1 layer & 12 & 7 & 164 \\
HDGS_U(900) 1 layer & 17 & 15 & 103 \\
HDGS_U(900):3.45TEOS 1 layer & 28 & 22 & 184 \\
HDGS_U(2000) 1 layer & 46 & 34 & 348 \\
HDGS_U(2000):3.45TEOS 1 layer & 35 & 25 & 326 \\
\hline
\end{tabular}

The coating quality and surface roughness play a role on the corrosion behavior of metallic materials. An increase in the surface roughness increases the pitting susceptibility and corrosion rate which is according to the literature [63]. The AFM and the EIS results are in agreement and show that, generally, as the MW of Jeffamine ${ }^{\circledR}$ increases, the roughness increases and the resistance of the hybrid coatings decreases which is also according to previous studies [27]. This tendency remains, even when the samples are enriched with TEOS. The results indicate that the corrosion behavior is not only dependent on coating quality but also on roughness, and the results have shown that samples with poor corrosion protection have high roughness, which is consistent with data found in the literature $[27,63,64]$.

\subsection{Open Circuit Potential (OCP) and Polarization Resistance $\left(R_{p}\right)$ Measurements}

The OCP and $R_{p}$ measurements were performed daily. The information extracted from OCP results indicates either a low or high probability of corrosion occurrence but it does not provide information on the corrosion rate [65-67]. The $R_{p}$ measurements represent the instantaneous corrosion current density. These measurements allow to assess the condition of the embedded steel reinforcement related to its corrosion [65]. Figure 11 shows the OCP values obtained for each sample. Generally, coated samples show an increase in the OCP variation over time and the values are always higher 
than those obtained for the control sample. This behavior indicates that coated samples have low probability of corrosion occurrence (higher OCP values) compared to control samples (lower OCP values). After chloride addition the initial drop in the OCP values can be observed in all cases followed by an increase over time for coated samples, whereas the control sample display almost constant OCP values. Again, the OCP results indicate that coated samples, even in the presence of chloride ions, have lower probability of corrosion occurrence compared to control samples.

Table 8 shows the $R_{p}$ values obtained on the Days 1, 7, 9 and 16 of immersion. Generally, coated samples show an increase in the $R_{p}$ values after seven days of immersion (Table 8), whereas the control samples show a significant decrease. Furthermore, low $R_{p}$ values were obtained for the control samples on Day 7 when compared to all the coated samples that showed higher $R_{p}$ values (between $10^{3}$ and $10^{5}$ $\Omega \cdot \mathrm{cm}^{2}$ ). The behavior displayed by the control samples is explained by the zinc corrosion process in alkaline environments $[16,66,67]$. For high $\mathrm{pH}$ values, the passivation of the surface of the substrate is difficult to reach and $\mathrm{Zn}$ dissolution continues until all the zinc has been dissolved. After $\mathrm{Cl}^{-}$addition a sharp decrease of $R_{p}$ values was registered for control samples and samples coated with three layers. Nevertheless, the values remained above those obtained for control samples. Improved results (high $R_{p}$ values) were obtained by coating HDGS with only one layer of U(900) with TEOS and U(600) with and without TEOS, even after $\mathrm{Cl}^{-}$addition.
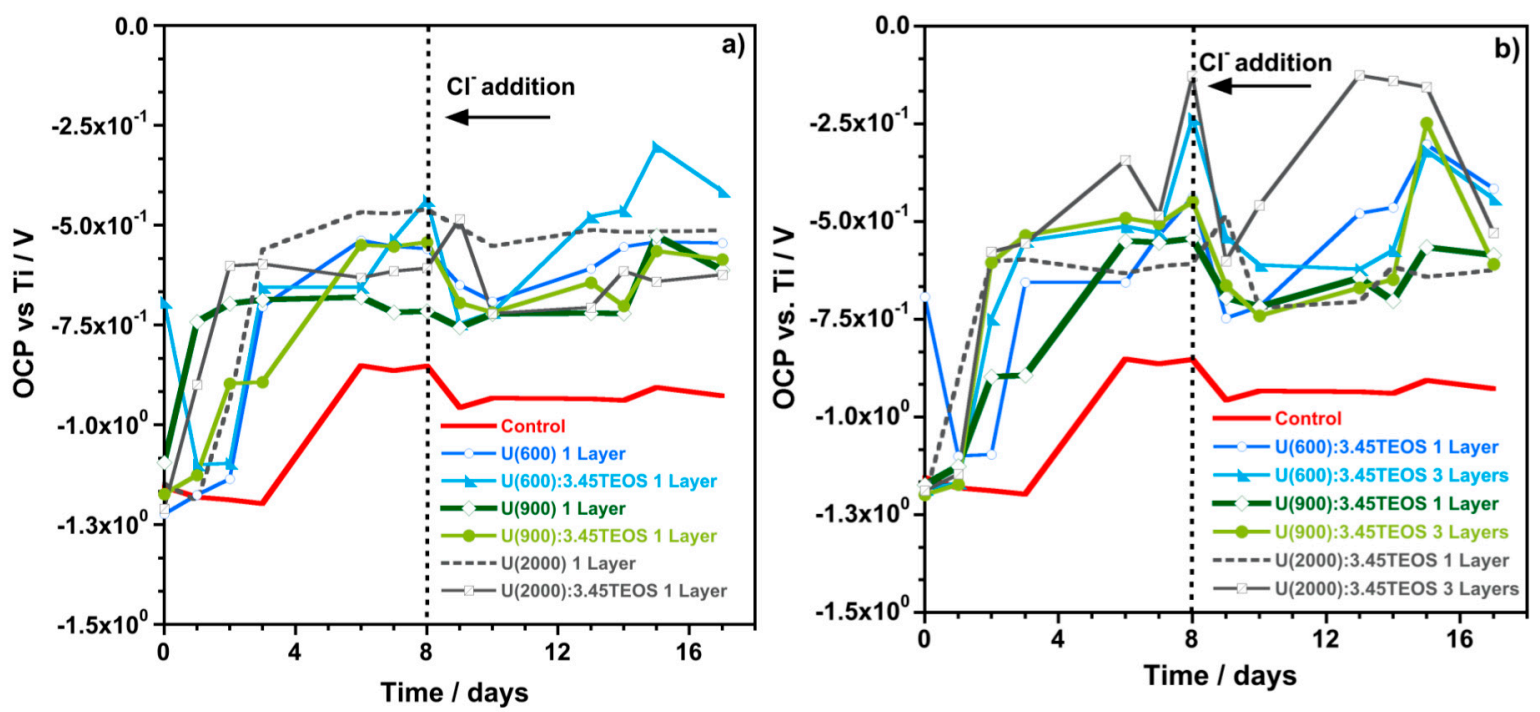

Figure 11. OCP variation over time recorded for the different coated HDGS sample cells kept embedded in SCPS for 17 days. Displayed graphs match to different urea-silicate matrices with and without TEOS: (a) $U(X)$ and $U(X): 3.45 T E O S$ samples deposited by one dip step (one layer); and (b) $U(X): 3.45 T E O S$ deposited by three dip steps (three layers).

After sixteen days of immersion, Table 8 shows that the $R_{p}$ values of the control samples did not change significantly and are considerably lower than those measured for coated samples. The results indicate that, on Day 16, the instantaneous corrosion current density reported for control samples is much higher compared to the values obtained for samples coated with one or three layers of hybrid with or without TEOS. Samples coated with one layer of U(2000):3.45TEOS and $\mathrm{U}(600): 3.45 T E O S$ provided higher and poorer corrosion protection, respectively. Samples coated with three layers of U(600):3.45TEOS and U(900)3.45TEOS provided the highest and the poorest corrosion protection, respectively.

Generally, AFM and $R_{p}$ data show that, by TEOS incorporation into the hybrid matrices, the samples show improved corrosion behavior and lower roughness values $\left(R_{a}\right.$ and $\left.R_{q}\right)$. This study also points out that the OCP, $R_{p}$ and EIS results are generally in agreement and samples enriched with TEOS, regardless the MW of Jeffamine ${ }^{\circledR}$ used, show improved results in terms of higher resistance 
values and improved corrosion behavior. A higher degree of crosslinking was expected for samples enriched with TEOS, which would explain the improvement of the corrosion behavior. On the contrary, the NMR study pointed out that the TEOS addition does not lead to relevant structural changes in the hybrid network. Therefore, the results suggest that the tetraalkoxysilane (TEOS) could have a role as a coupling agent, providing improved affinity between the organic component and the metallic substrate by means of the interaction between $\mathrm{Si}-\mathrm{OH}$ and metal-OH (native oxide layer of HDGS) [31]. Nevertheless, no further conclusions can be drawn.

Table 8. $R_{p}$ values obtained for the different coatings prepared with different ratios of TEOS.

\begin{tabular}{cccccc}
\hline Samples & $\begin{array}{c}\text { Number of } \\
\text { Layers }\end{array}$ & Day 1 & $\begin{array}{c}\text { Before } \mathrm{Cl}^{-} \text {Addition } \\
\text { (Day 7) }\end{array}$ & $\begin{array}{c}\text { After } \mathrm{Cl}^{-} \text {Addition } \\
\text { (Day 9) }\end{array}$ & Day 16 \\
\hline & & $\left(\Omega \cdot \mathrm{cm}^{2}\right) \times 10^{3}$ & $\left(\Omega \cdot \mathrm{cm}^{2}\right) \times 10^{3}$ & $\left(\Omega \cdot \mathrm{cm}^{2}\right) \times 10^{3}$ & $\left(\Omega \cdot \mathrm{cm}^{2}\right) \times 10^{3}$ \\
\hline Control & & $0.649 \pm 0.188$ & $0.023 \pm 0.007$ & $0.008 \pm 0.002$ & $0.009 \pm 0.003$ \\
\hline $\mathrm{U}(600)$ & & & & \\
\hline $1: 4.16: 0$ & 1 & $0.238 \pm 0.042$ & $21.5 \pm 3.8$ & $32.1 \pm 5.6$ & $153 \pm 27$ \\
$1: 4.16: 3.45$ & 1 & $16.4 \pm 4.8$ & $14.6 \pm 4.2$ & $14.6 \pm 5.3$ & $0.024 \pm 0.007$ \\
$1: 4.16: 3.45$ & 3 & $2.94 \pm 0.53$ & $32.6 \pm 5.9$ & $0.018 \pm 0.003$ & $73.2 \pm 13.2$ \\
\hline $\mathrm{U}(900)$ & & & & & \\
\hline $1: 4.16: 0$ & 1 & $3.67 \pm 0.64$ & $314 \pm 55$ & $0.040 \pm 0.007$ & $0.044 \pm 0.008$ \\
$1: 4.16: 3.45$ & 1 & $0.004 \pm 0.001$ & $141 \pm 21$ & $354 \pm 53.1$ & $118 \pm 18$ \\
$1: 4.16: 3.45$ & 3 & $0.192 \pm 0.052$ & $37.3 \pm 10.1$ & $0.035 \pm 0.009$ & $0.129 \pm 0.035$ \\
\hline $\mathrm{U}(2000)$ & & & & & \\
$1: 4.16: 0$ & 1 & $31.8 \pm 0.5$ & $12.1 \pm 1.82$ & $0.389 \pm 0.058$ & $0.424 \pm 0.064$ \\
$1: 4.16: 3.45$ & 1 & $0.120 \pm 0.033$ & $5.78 \pm 1.58$ & $13.7 \pm 3.8$ & $257 \pm 71$ \\
$1: 4.16: 3.45$ & 3 & $0.489 \pm 0.134$ & $145 \pm 40$ & $0.018 \pm 0.005$ & $0.557 \pm 0.153$ \\
\hline
\end{tabular}

\section{Conclusions}

The present work reports the effect of TEOS addition into ureasilicate matrices on the structural properties of the hybrid sol-gel materials and on the corrosion behavior in chloride-contaminated SCPS.

The NMR results point to conclusion that: (i) the reaction between the polymer amino groups and the $\mathrm{N}=\mathrm{C}=\mathrm{O}$ end group of ICPTES takes place; (ii) when using ICPTES in excess, urea and urethane bridges are created immediately after the mixing of the reagents, but the formation of the - HNCONHbridge is favored; (iii) these bridges remain stable upon carboxylic acid addition; and (iv) the addition of TEOS seems not to affect the organic structure of the hybrid materials and does not increase the DOC of the hybrid materials. The NMR study also suggest the presence of several components in the amide band of ureasilicate samples due to polyethereamine chains with different hydrogen bonding interactions. Moreover, the possible segregation of TEOS-derived domains can be assumed on the basis of cross polarization experiments. Additional studies should be conducted in order to understand these evidences.

EIS data show that, with increasing TEOS content, the resistance of the hybrid films increases. The electrochemical results obtained from monitoring cells (OCP and $\mathrm{R}_{\mathrm{p}}$ data) on HDGS coated samples exposed to SCPS (before and after chloride ion addition) show that all the samples display improved performance when compared to the control (the uncoated HDGS sample). OCP, $R_{p}$ and EIS results are, generally, in agreement, and the samples enriched with TEOS, regardless the MW of Jeffamine used, show superior corrosion behavior when compared to the hybrid samples without TEOS. Taking into account the structural study, it can also be concluded that the corrosion behavior is dependent on the coating quality, in particular the surface roughness. Indeed, the hybrid samples with superior corrosion protection display low roughness parameters and roughness decreases with TEOS addition. Moreover, the metal-coating interaction could be improved by increasing the inorganic moiety in $U(X)$ hybrids. The results point to the conclusion that the ureasilicate coatings enriched with TEOS have favorable properties to be employed as pre-treatments to reduce corrosion activity during 
the initial stages of contact of the HDGS samples with highly alkaline environments $(\mathrm{pH}>12.5)$ and in the presence of aggressive species such as chloride ions.

Further work has to be performed in the future in order to understand medium- and long-term performance of these hybrid systems. Moreover, studying in depth the metal-coating interface appears a tool for a full understanding of the hybrid coatings behavior. The auspicious progress demonstrated by this study suggests that these materials can be successfully used in the field of functional coatings. Studies on different substrates and environments should be carried out because these materials may potentially be used in a wide number of areas, such as automotive field, optical and photovoltaic devices, and consumer goods.

Supplementary Materials: The following are available online at www.mdpi.com/1996-1944/10/3/306/s1. Figure S1: ${ }^{13} \mathrm{C}-\mathrm{NMR}$ of the mixture Jeffamine $600 /$ ICPTES (1:4) in ethanol- $d_{6}$ immediately after mixing and after $24 \mathrm{~h}$ and with subsequent addition of citric acid, Figure S2: Lowfield part of the ${ }^{13} \mathrm{C}$ CPMAS spectrum of U(900):3.45TEOS, Figure S3: ${ }^{29} \mathrm{Si}$ CPMAS NMR spectra of hybrid samples prepared with and without TEOS.

Acknowledgments: The authors would like to gratefully acknowledge the financial support from Fundação para a Ciência e Tecnologia (FCT) for the PhD grant SFRH/BD/62601/2009 and to Hugo Gomes for assisting in the execution of Figures 2 and 3. The research was performed within the frame of COST Action MP1202 (HINT) "Rational design of hybrid organic/inorganic interfaces: the next step towards advanced functional materials". The COST action MP1202 (HINT) is acknowledged for providing funding for COST-STSM-MP1202-32076 grant that contributed to this research project.

Author Contributions: Rita B. Figueira performed the synthesis of the hybrid materials, EIS and AFM measurements and respective data analysis. Emanuela Callone performed the NMR measurements of the hybrid materials. Emanuela Callone and Sandra Dirè analyzed all the NMR data. All data were analyzed by Rita B. Figueira, Emanuela Callone and Carlos J. R. Silva. Rita B. Figueira and Emanuela Callone wrote the manuscript with contributions from Carlos J. R. Silva, Sandra Dirè and Elsa V. Pereira. All authors have given approval to the final version of the manuscript.

Conflicts of Interest: The authors declare no conflict of interest.

\section{References}

1. Bardal, E. (Ed.) Corrosion and Protection; Springer: London, UK, 2004.

2. Böhni, H. Corrosion in Reinforced Concrete Structures; Böhni, H., Ed.; Woodhead Publishing Ltd.: Cambridge, UK, 2005.

3. Raupach, M.; Elsener, B.; Polder, R.; Mietz, J. Corrosion of Reinforcement in Concrete: Mechanisms, Monitoring, Inhibitors and Rehabilitation Techniques; Woodhead; CRC Press: Cambridge, UK; Boca Raton, FL, USA, 2007.

4. Zhu, X.; Zi, G.; Lee, W.; Kim, S.; Kong, J. Probabilistic analysis of reinforcement corrosion due to the combined action of carbonation and chloride ingress in concrete. Constr. Build. Mater. 2016, 124, 667-680. [CrossRef]

5. Andrade, C. 14-Future trends in research on reinforcement corrosion A2-Poursaee, Amir. In Corrosion of Steel in Concrete Structures; Woodhead Publishing: Oxford, UK, 2016; pp. 269-288.

6. Liberati, E.A.P.; Nogueira, C.G.; Leonel, E.D.; Chateauneuf, A. Chapter 5-Failure analysis of reinforced concrete structures subjected to chloride penetration and reinforcements corrosion A2-Makhlouf, Abdel Salam Hamdy. In Handbook of Materials Failure Analysis with Case Studies from the Chemicals, Concrete and Power Industries; Aliofkhazraei, M., Ed.; Butterworth-Heinemann: Oxford, UK, 2016; pp. 93-121.

7. Page, C.L.; Treadaway, K.W.J. Aspects of the electrochemistry of steel in concrete. Nature 1982, 297, 109-115. [CrossRef]

8. Narasimhan, H.; Chew, M.Y.L. Integration of durability with structural design: An optimal life cycle cost based design procedure for reinforced concrete structures. Constr. Build. Mater. 2009, 23, 918-929. [CrossRef]

9. Zeng, X.; Wang, Z.; Fan, J.; Zhao, L.; Lin, D.; Zhao, J. Problems of durability and reinforcement measures for underground structures in China. J. Rock Mech. Geotech. Eng. 2011, 3, 250-259. [CrossRef]

10. Claisse, P.A. Chapter 25-Durability of concrete structures. In Civil Engineering Materials; Butterworth-Heinemann: Boston, MA, USA, 2016; pp. 259-274.

11. Yohai, L.; Vázquez, M.; Valcarce, M.B. Phosphate ions as corrosion inhibitors for reinforcement steel in chloride-rich environments. Electrochim. Acta 2013, 102, 88-96. [CrossRef]

12. Silva, R.V.; de Brito, J.; Dhir, R.K. Properties and composition of recycled aggregates from construction and demolition waste suitable for concrete production. Constr. Build. Mater. 2014, 65, 201-217. [CrossRef] 
13. Blunt, J.; Jen, G.; Ostertag, C.P. Enhancing corrosion resistance of reinforced concrete structures with hybrid fiber reinforced concrete. Corros. Sci. 2015, 92, 182-191. [CrossRef]

14. Ormellese, M.; Berra, M.; Bolzoni, F.; Pastore, T. Corrosion inhibitors for chlorides induced corrosion in reinforced concrete structures. Cem. Concr. Res. 2006, 36, 536-547. [CrossRef]

15. Bonić, Z.; Ćurčić, G.T.; Trivunić, M.; Davidović, N.; Vatin, N. Some Methods of Protection of Concrete and Reinforcment of Reinforced-Concrete Foundations exposed to Environmental Impacts. Procedia Eng. 2015, 117, 419-430. [CrossRef]

16. Yeomans, S.R. International Lead Zinc Research Organization. In Galvanized Steel Reinforcement in Concrete; Elsevier: Amsterdam, The Netherlands, 2004.

17. Bird, C.E. The Influence of Minor Constituents of Portland Cement on the Behaviour of Galvanized Steel in Concrete; South African Council for Scientific and Industrial Research: Pretoria, South Africa, 1964.

18. Recio, F.J.; Alonso, M.C.; Gaillet, L.; Sánchez, M. Hydrogen embrittlement risk of high strength galvanized steel in contact with alkaline media. Corros. Sci. 2011, 53, 2853-2860. [CrossRef]

19. Macias, A. Comparison of different electrochemical techniques for corrosion-rate determination of zinc-coated reinforcements in simulated concrete pore solutions. Mater. Struct. 1991, 24, 456-465. [CrossRef]

20. Blanco, M.T.; Andrade, C.; Macias, A. SEM Study of the Corrosion Products of Galvanized Reinforcements Immersed in Solutions in the $\mathrm{pH}$ Range $12 \cdot 6$ to 13.6. Br. Corros. J. 1984, 19, 41-48. [CrossRef]

21. Li, M.C.; Royer, M.; Stien, D.; Lecante, A.; Roos, C. Inhibitive effect of sodium eperuate on zinc corrosion in alkaline solutions. Corros. Sci. 2008, 50, 1975-1981. [CrossRef]

22. Farina, S.B.; Duffó, G.S. Corrosion of zinc in simulated carbonated concrete pore solutions. Electrochim. Acta 2007, 52, 5131-5139. [CrossRef]

23. Bellezze, T.; Saltykov, S.; Roventi, G.; Malavolta, M.; Fratesi, R. Layer-by-layer analysis of hot-dip zinc coating by anodic dissolution in acetate bath. Surf. Coat. Technol. 2012, 206, 5023-5027. [CrossRef]

24. Tittarelli, F.; Bellezze, T. Investigation of the major reduction reaction occurring during the passivation of galvanized steel rebars. Corros. Sci. 2010, 52, 978-983. [CrossRef]

25. Figueira, R.B.; Silva, C.J.R.; Pereira, E.V. Organic-inorganic hybrid sol-gel coatings for metal corrosion protection: A review of recent progress. J. Coat. Technol. Res. 2014, 12, 1-35. [CrossRef]

26. Fedel, M.; Poelman, M.; Zago, M.; Vandermiers, C.; Cossement, D.; Olivier, M.-G.; Deflorian, F. Influence of formulation and application parameters on the performances of a sol-gel/clay nanocomposite on the corrosion resistance of hot-dip galvanized steel, Part II. Effect of curing temperature and time. Surf. Coat. Technol. 2015, 274, 9-17. [CrossRef]

27. Figueira, R.B.; Silva, C.J.R.; Pereira, E.V. Hybrid sol-gel coatings for corrosion protection of galvanized steel in simulated concrete pore solution. J. Coat. Technol. Res. 2016, 13, 355-373. [CrossRef]

28. Yasakau, K.A.; Carneiro, J.; Zheludkevich, M.L.; Ferreira, M.G.S. Influence of sol-gel process parameters on the protection properties of sol-gel coatings applied on AA2024. Surf. Coat. Technol. 2014, 246, 6-16. [CrossRef]

29. Maia, F.; Yasakau, K.A.; Carneiro, J.; Kallip, S.; Tedim, J.; Henriques, T.; Cabral, A.; Venâncio, J.; Zheludkevich, M.L.; Ferreira, M.G.S. Corrosion protection of AA2024 by sol-gel coatings modified with MBT-loaded polyurea microcapsules. Chem. Eng. J. 2016, 283, 1108-1117. [CrossRef]

30. Su, H.-Y.; Chen, P.-L.; Lin, C.-S. Sol-gel coatings doped with organosilane and cerium to improve the properties of hot-dip galvanized steel. Corros. Sci. 2016, 102, 63-71. [CrossRef]

31. Suzana, A.F.; Ferreira, E.A.; Benedetti, A.V.; Carvalho, H.W.P.; Santilli, C.V.; Pulcinelli, S.H. Corrosion protection of chromium-coated steel by hybrid sol-gel coatings. Surf. Coat. Technol. 2016, 299, 71-80. [CrossRef]

32. Figueira, R.B.; Silva, C.J.; Pereira, E.V.; Salta, M.M. Ureasilicate Hybrid Coatings for Corrosion Protection of Galvanized Steel in Cementitious Media. J. Electrochem. Soc. 2013, 160, C467-C479. [CrossRef]

33. Figueira, R.B.; Silva, C.J.R.; Pereira, E.V. Hot-dip galvanized steel dip-coated with ureasilicate hybrid in simulated concrete pore solution: Assessment of coating morphology and corrosion protection efficiency. Prog. Org. Coat. 2015, 88, 245-255. [CrossRef]

34. Figueira, R.B.; Silva, C.J.R.; Pereira, E.V. Influence of Experimental Parameters Using the Dip-Coating Method on the Barrier Performance of Hybrid Sol-Gel Coatings in Strong Alkaline Environments. Coatings 2015, 5, 124-141. [CrossRef]

35. Figueira, R.B.; Silva, C.J.R.; Pereira, E.V. Hybrid sol-gel coatings for corrosion protection of hot-dip galvanized steel in alkaline medium. Surf. Coat. Technol. 2015, 265, 191-204. [CrossRef] 
36. Figueira, R.B.; Silva, C.J.; Pereira, E.V. Ureasilicate Hybrid Coatings for Corrosion Protection of Galvanized Steel in Chloride-Contaminated Simulated Concrete Pore Solution. J. Electrochem. Soc. 2015, 162, C666-C676. [CrossRef]

37. Boev, V.I.; Soloviev, A.; Silva, C.J.R.; Gomes, M.J.M. Incorporation of CdS nanoparticles from colloidal solution into optically clear ureasilicate matrix with preservation of quantum size effect. Solid State Sci. 2006, 8, 50-58. [CrossRef]

38. Brinker, C.J.; Scherer, G.W. Sol-Gel Science: The Physics and Chemistry of Sol-Gel Processing; Academic Press: Boston, MA, USA, 1990.

39. Karmakar, B.; De, G.; Ganguli, D. Dense silica microspheres from organic and inorganic acid hydrolysis. J. Non-Cryst. Solids 2000, 272, 119-126. [CrossRef]

40. Silva, C.J.R.; Smith, M.J. Preparative effects on poly(ethylene oxide) based polymer electrolytes of lanthanide salts. Electrochim. Acta 1995, 40, 2389-2392. [CrossRef]

41. Macias, A.; Andrade, C. The behaviour of galvanized steel in chloride-containing alkaline solutions-I. The influence of the cation. Corros. Sci. 1990, 30, 393-407. [CrossRef]

42. Moreno, M.; Morris, W.; Alvarez, M.G.; Duffó, G.S. Corrosion of reinforcing steel in simulated concrete pore solutions. Corros. Sci. 2004, 46, 2681-2699. [CrossRef]

43. Pereira, E.V.; Figueira, R.B.; Salta, M.M.L.; da Fonseca, I.T.E. A Galvanic Sensor for Monitoring the Corrosion Condition of the Concrete Reinforcing Steel: Relationship between the Galvanic and the Corrosion Currents. Sensors 2009, 9, 8391-8398. [CrossRef] [PubMed]

44. Andrade, C.; Alonso, C. Corrosion rate monitoring in the laboratory and on-site. Constr. Build. Mater. 1996, 10, 315-328. [CrossRef]

45. Pereira, E.V.; Salta, M.M.; Fonseca, I.T.E. On the measurement of the polarisation resistance of reinforcing steel with embedded sensors: A comparative study. Mater. Corros. 2015. [CrossRef]

46. Castro, P.; Sagüés, A.A.; Moreno, E.I.; Maldonado, L.; Genescá, J. Characterization of Activated Titanium Solid Reference Electrodes for Corrosion Testing of Steel in Concrete. Corrosion 1996, 52, 609-617. [CrossRef]

47. Pereira, E.V.; Figueira, R.B.; Salta, M.M.; Fonseca, I.T.E. Embedded Sensors for Corrosion Monitoring of Existing Reinforced Concrete Structures. Mater. Sci. Forum 2008, 587-588, 677-681. [CrossRef]

48. Froimowicz, P.; Gandini, A.; Strumia, M. New polyfunctional dendritic linear hybrids from terminal amine polyether oligomers: Synthesis and characterization. Tetrahedron Lett. 2005, 46, 2653-2657. [CrossRef]

49. Saikia, D.; Pan, Y.-C.; Kao, H.-M. Synthesis, Multinuclear NMR Characterization and Dynamic Property of Organic-Inorganic Hybrid Electrolyte Membrane Based on Alkoxysilane and Poly(oxyalkylene) Diamine. Membranes 2012, 2, 253-274. [CrossRef] [PubMed]

50. Schilling, F.C.; Tonelli, A.E. Carbon-13 NMR determination of poly(propylene oxide) microstructure. Macromolecules 1986, 19, 1337-1343. [CrossRef]

51. Zhang, G.; Dass, A.; Rawashdeh, A.-M.M.; Thomas, J.; Counsil, J.A.; Sotiriou-Leventis, C.; Fabrizio, E.F.; Ilhan, F.; Vassilaras, P.; Scheiman, D.A.; et al. Isocyanate-crosslinked silica aerogel monoliths: Preparation and characterization. J. Non-Cryst. Solids 2004, 350, 152-164. [CrossRef]

52. Okamoto, D.T.; Cooper, S.L.; Root, T.W. Carbon-13 NMR investigation of a poly(urethane-urea) system. Macromolecules 1992, 25, 1068-1073. [CrossRef]

53. De Zea Bermudez, V.; Carlos, L.D.; Alcácer, L. Sol-Gel Derived Urea Cross-Linked Organically Modified Silicates. 1. Room Temperature Mid-Infrared Spectra. Chem. Mater. 1999, 11, 569-580. [CrossRef]

54. Ansell, R.J.; Barrett, S.A.; Meegan, J.E.; Warriner, S.L. On the Interactions of Alkyl 2-Hydroxycarboxylic Acids with Alkoxysilanes: Selective Esterification of Simple 2-Hydroxycarboxylic Acids. Chem. Eur. J. 2007, 13, 4654-4664. [CrossRef] [PubMed]

55. Borovin, E.; Callone, E.; Ceccato, R.; Quaranta, A.; Dirè, S. Adsorptive properties of sol-gel derived hybrid organic/inorganic coatings. Mater. Chem. Phys. 2014, 147, 954-962. [CrossRef]

56. Barsoukov, E.; Macdonald, J.R. Impedance Spectroscopy: Theory, Experiment, and Applications; Wiley: Hoboken, NJ, USA, 2005.

57. Orazem, M.E.; Tribollet, B. Electrochemical Impedance Spectroscopy; Wiley: Hoboken, NJ, USA, 2008.

58. Hirschorn, B.; Orazem, M.E.; Tribollet, B.; Vivier, V.; Frateur, I.; Musiani, M. Determination of effective capacitance and film thickness from constant-phase-element parameters. Electrochim. Acta 2010, 55, 6218-6227. [CrossRef] 
59. Amand, S.; Musiani, M.; Orazem, M.E.; Pébère, N.; Tribollet, B.; Vivier, V. Constant-phase-element behavior caused by inhomogeneous water uptake in anti-corrosion coatings. Electrochim. Acta 2013, 87, 693-700. [CrossRef]

60. Figueira, R.B.; Silva, C.J.; Pereira, E.V.; Salta, M.M. Alcohol-Aminosilicate Hybrid Coatings for Corrosion Protection of Galvanized Steel in Mortar. J. Electrochem. Soc. 2014, 161, C349-C362. [CrossRef]

61. Bierwagen, G.; Tallman, D.; Li, J.; He, L.; Jeffcoate, C. EIS studies of coated metals in accelerated exposure. Prog. Org. Coat. 2003, 46, 149-158. [CrossRef]

62. Leidheiser, H. Electrical and electrochemical measurements as predictors of corrosion at the metal-organic coating interface. Prog. Org. Coat. 1979, 7, 79-104. [CrossRef]

63. Zhao, H.; Yu, M.; Liu, J.; Li, S.; Xue, B.; Liang, M. Effect of Surface Roughness on Corrosion Resistance of Sol-Gel Coatings on AA2024-T3 Alloy. J. Electrochem. Soc. 2015, 162, C718-C724. [CrossRef]

64. Shahryari, A.; Kamal, W.; Omanovic, S. The effect of surface roughness on the efficiency of the cyclic potentiodynamic passivation (CPP) method in the improvement of general and pitting corrosion resistance of 316LVM stainless steel. Mater. Lett. 2008, 62, 3906-3909. [CrossRef]

65. Andrade, C.; Alonso, C. Test methods for on-site corrosion rate measurement of steel reinforcement in concrete by means of the polarization resistance method. Mater. Struct. 2004, 37, 623-643. [CrossRef]

66. Macías, A.; Andrade, C. Stability of the calcium hydroxizincate protective layer developed on galvanized reinforcement after a further increase of the $\mathrm{pH}$ value. Mater. Construccion 1986, 36, 19-27. [CrossRef]

67. Figueira, R.B.; Silva, C.J.R.; Pereira, E.V.; Salta, M.M. Corrosion of Hot-Dip Galvanized Steel Reinforcement. Corros. E Prot. Mater. 2014, 33, 51-61.

(C) 2017 by the authors. Licensee MDPI, Basel, Switzerland. This article is an open access article distributed under the terms and conditions of the Creative Commons Attribution (CC BY) license (http:/ / creativecommons.org/licenses/by/4.0/). 